\title{
Global changes in STAT target selection and transcription regulation upon interferon treatments
}

\author{
Stephen E. Hartman, ${ }^{1}$ Paul Bertone, ${ }^{1,2}$ Anjali K. Nath,${ }^{1}$ Thomas E. Royce, ${ }^{2}$ Mark Gerstein, ${ }^{2}$ \\ Sherman Weissman, ${ }^{3}$ and Michael Snyder ${ }^{1,2,4}$ \\ ${ }^{1}$ Department of Molecular, Cellular, and Developmental Biology, ${ }^{2}$ Department of Molecular Biophysics and Biochemistry, \\ and ${ }^{3}$ Department of Genetics, Yale University, New Haven, Connecticut 06520, USA
}

The STAT (signal transducer and activator of transcription) proteins play a crucial role in the regulation of gene expression, but their targets and the manner in which they select them remain largely unknown. Using chromatin immunoprecipitation and DNA microarray analysis (ChIP-chip), we have identified the regions of human chromosome 22 bound by STAT1 and STAT2 in interferon-treated cells. Analysis of the genomic loci proximal to these binding sites introduced new candidate STAT1 and STAT2 target genes, several of which are affiliated with proliferation and apoptosis. The genes on chromosome 22 that exhibited interferon-induced up- or down-regulated expression were determined and correlated with the STAT-binding site information, revealing the potential regulatory effects of STAT1 and STAT2 on their target genes. Importantly, the comparison of STAT1-binding sites upon interferon (IFN)- $\gamma$ and IFN- $\alpha$ treatments revealed dramatic changes in binding locations between the two treatments. The IFN- $\alpha$ induction revealed nonconserved STAT1 occupancy at IFN- $\gamma$-induced sites, as well as novel sites of STAT1 binding not evident in IFN- $\gamma$-treated cells. Many of these correlated with binding by STAT2, but others were STAT2 independent, suggesting that multiple mechanisms direct STAT1 binding to its targets under different activation conditions. Overall, our results reveal a wealth of new information regarding IFN/STAT-binding targets and also fundamental insights into mechanisms of regulation of gene expression in different cell states.

[Keywords: STAT1; STAT2; interferon; ChIP-chip; microarray; chromosome 22]

Supplemental material is available at http://www.genesdev.org.

Received September 1, 2005; revised version accepted October 17, 2005.

The binding of transcription factors to specific DNA sequences determines the populations of target genes to be expressed and how their transcription is regulated. Mapping transcription factor-binding sites and identifying these target genes remains an imposing obstacle to understanding the complex nature of gene regulatory networks. Furthermore, identification of the sites bound by transcription factors under different activation conditions is necessary to fully address many questions regarding transcriptional regulation. Of particular interest is how the selection of binding sites varies after activation by different stimuli. Do interactions between cooperating transcription factors affect their binding site selection? Do these interactions completely redirect the binding of existing factors to new sites or only a subset of sites? Do additional new sites become available under new conditions? Ultimately, what is the effect on the

${ }^{4}$ Corresponding author

E-MAIL michael.snyder@yale.edu; FAX (203) 432-6161.

Article published online ahead of print. Article and publication date are at http://www.genesdev.org/cgi/doi/10.1101/gad.1371305. transcriptional regulation of target genes? With the advances in genomics technologies, we can now explore these and many other questions regarding the intricate circuitry of transcriptional regulation.

The STAT (signal transducer and activator of transcription) family of proteins mediates the transcriptional responses to many cytokines and growth factors and is a useful system for studying inducible gene regulation. Different stimuli trigger the JAK-STAT pathway to phosphorylate latent, cytosolic STAT monomers, allowing them to form homo- and/or heterodimers. These stimuli induce the formation of different STAT dimer combinations, which in turn bind to specific DNA target sites and regulate the transcription of genes involved in proliferation, differentiation, apoptosis, antiviral response, inflammation, and immune response (for reviews, see Ramana et al. 2000; Levy and Darnell 2002). Since their discovery more than 10 years ago, much research has focused on understanding STAT activation, regulation, structure, and the phenotypic effects of their absence. However, significantly less progress has been made toward identifying the specific STAT-regulated 
genes crucial for mediating the biological effects of the interferons (IFNs) and determining how these targets are selected.

In this study we have focused on the behavior of STAT1 and STAT2 after treatment of cells with IFNs. The IFNs influence vital biological processes such as antiviral defense responses, regulation of cell proliferation, apoptosis, and immune responses primarily by modulating gene expression via the JAK/STAT pathway (Boehm et al. 1997; Stark et al. 1998). These effects have given the IFNs major therapeutic value in the treatment of hepatitis, melanoma, leukemia, lymphoma, and multiple sclerosis, although their mechanism of action is still unclear (Pfeffer et al. 1998). Several recent reports have identified hundreds of IFN-responsive genes, but the specific factors responsible for regulating these genes have not been identified (Der et al. 1998; Certa et al. 2001; Ji et al. 2003; Leaman et al. 2003).

STAT1 and STAT2 play an important role in IFN responses. STAT1 regulates proliferation by promoting growth arrest and apoptosis in response to IFN signals (Bromberg et al. 1996; Ramana et al. 2000). STAT1-null mice display enhanced tumorigenesis and severe susceptibility to microbial and viral infections, further supporting a role for STAT1 in growth restraint and resistance to infections (Durbin et al. 1996; Meraz et al. 1996; Kaplan et al. 1998). STAT2 is a vital component of IFN- $\alpha$-regulated processes, and its absence severely dismantles immune responses and IFN- $\alpha$ sensitivity (Park et al. 2000). Since STAT-DNA interactions are important determinants in the selection of IFN-regulated target genes, it is obviously important to directly identify the locations of these sites.

IFN- $\gamma$ (type II IFN) induces the phosphorylation of STAT1 and promotes the formation of STAT1 homodimers, which recognize GAS ( $\gamma$-activated sequence) elements. IFN- $\alpha$ (type I IFN) stimulation results in the phosphorylation of both STAT1 and STAT2, thus producing STAT1 homodimers and STAT1:STAT2 heterodimers (known as ISGF3 when complexed with IRF9). ISGF3 recognizes ISRE (IFN-stimulated response element) motifs (Li et al. 1996). The regulation of STAT1 by both IFN- $\gamma$ and IFN- $\alpha$ provides a useful system to understand how transcription factors select distinct binding sites under different activation conditions. Of particular interest is how the presence of activated STAT2 affects the DNA-binding behavior of STAT1 homodimers, including whether homodimer sites are equally utilized during the concurrent formation of STAT1:STAT2 heterodimers, or whether DNA-binding patterns shift in the presence of a new dimerization partner, possibly with additional sites becoming available under different stimulation conditions. Since the different STAT dimers display different DNA-binding behaviors, determining the binding sites of individual STAT family members will help further clarify the mechanisms by which transcription factors select their targets.

We have used the chromatin immunoprecipitation and DNA microarray analysis (ChIP-chip) approach to identify the locations on human chromosome 22 to which STAT1 and STAT2 bind after IFN- $\gamma$ and/or IFN- $\alpha$ stimulation. This technique uses microarrays to analyze the contents of DNA samples isolated by ChIP of a DNA-binding protein (Ren et al. 2000; Iyer et al. 2001). When used in conjunction with microarrays containing unbiased genomic sequences, this assay can identify the locations of direct, in vivo protein-DNA interactions. This study utilizes a microarray that represents nearly all of the unique, nonrepetitive sequence of human chromosome 22, thus allowing for chromosome-wide surveys of STAT1- and STAT2-binding sites (Martone et al. 2003; Rinn et al. 2003; Euskirchen et al. 2004). We also determined the IFN- $\alpha$ - and IFN- $\gamma$-dependent changes in gene expression on chromosome 22 in order to develop a better functional understanding of the STAT-DNA interactions.

In the present study, we show that STAT1 and STAT2 each bind to many sites on chromosome 22. A large number of these binding sites lie proximal to annotated loci and IFN-regulated genes and thus introduce many new candidate target genes for STAT1 homodimers and STAT1:STAT2 heterodimers. Some of these genes are involved in IFN-influenced biological processes, such as growth suppression and apoptosis, while many others participate in functions not previously associated with the IFNs and/or STATs. Importantly, we analyzed STAT1 binding under different IFN treatments and demonstrate a complex mode of regulation. Upon IFN- $\alpha$ treatment, STAT1 does not bind all of its IFN- $\gamma$-induced sites. STAT1 cooperates with STAT2 to bind new targets but is also directed to new targets independent of STAT2. Therefore, STAT1 exhibits stimulus-dependent shifts in DNA-binding patterns, suggesting that the binding behavior of STAT1 homodimers is differentially regulated under different IFN-stimulation conditions. Thus, our results demonstrate that the IFNs and STATs display a large amount of previously unrecognized activity on human chromosome 22, and we have introduced novel mechanisms for the regulation of STAT1-binding site selection.

\section{Results}

\section{STAT1 and STAT2 ChIPs isolate STAT-bound DNA}

To examine the expression and activation of STAT1 and STAT2 and to identify antibodies suitable for ChIP experiments, we first analyzed STAT1 and STAT2 by immunoprecipitation and immunoblotting. STAT1 or STAT2 was immunoprecipitated from the nuclear extracts of HeLaS3 cells treated with or without IFN- $\gamma$ or IFN- $\alpha$. We observed the expected increase in nuclear localization of STAT 1 after IFN- $\gamma$ and IFN- $\alpha$ treatments as well as nuclear translocation of STAT2 in IFN- $\alpha$-activated cells. (Fig. 1A). STAT2 localization is not altered in IFN- $\gamma$-treated cells (data not shown). Low levels of STAT1 and STAT2 protein were detected in the nuclear extract of untreated cells, which may represent residual dephosphorylated STATs or may be the result of interactions between these STATs and other transcription 
A

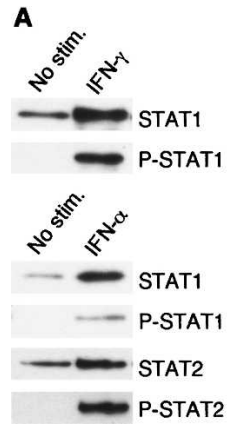

B

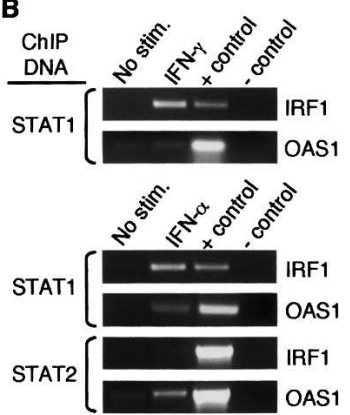

Figure 1. IFN stimulations activate the STATs and induce their binding to correct DNA target sequences. (A) Western blotting of STAT1 and STAT2 immunoprecipitations from nuclear extracts detected the increase in nuclear localization and phosphorylation of STAT1 and STAT2. (B) PCR analysis of STAT1 and STAT2 ChIP DNA confirmed the IFN-induced enriched presence of the STAT-binding sites in the IRF1 and OAS1 promoters. Positive and negative controls used genomic DNA and no template, respectively.

factors, as has been previously observed by others (Meyer et al. 2002). Probing the blots with anti-phospho-tyrosine-STAT1 or anti-phospho-tyrosine-STAT2 antibodies verified the IFN-induced activation of STAT1 and STAT2 in the appropriately stimulated cells.

To examine the DNA-binding behavior of STAT1 and STAT2, we isolated the DNA bound by each factor using ChIP and tested it for the enrichment of known STAT targets using PCR. HeLaS3 cells were stimulated with or without IFN- $\gamma$ or IFN- $\alpha$ for 30 min to induce maximal STAT nuclear localization (Bromberg and Chen 2001). After formaldehyde treatment to cross-link the proteinDNA interactions, nuclear-enriched extracts were prepared and sonicated to shear the chromatin, and STAT1 or STAT2 was immunoprecipitated. The STAT-bound DNA was purified and tested by PCR for the presence of the known STAT-binding sites upstream of IRF1 and OAS1. An enriched quantity of the IRF1 promoter fragment was found in both the IFN- $\gamma$ - and IFN- $\alpha$-induced STAT1 ChIP DNA samples relative to the uninduced condition, as expected (Fig. 1B). Enrichment of the OAS1 promoter fragment was observed only in the IFN- $\alpha$ treated STAT1 and STAT2 ChIP DNA samples, also as expected. No IFN-induced enrichment was detected in the promoter regions of negative control genes (data not shown). These results confirm that IFN- $\gamma$ and IFN- $\alpha$ induce STAT1 and STAT2 to specifically bind appropriate target DNA sequences, and also verify that the ChIP procedure accurately isolates the STAT1- and STAT2bound DNA.

\section{STAT1 and STAT2 ChIP-chip assays identify many binding sites on chromosome 22}

To identify STAT-binding sites on a larger scale, STAT1 and STAT2 ChIP DNA was used to probe a chromosome 22 DNA microarray. This microarray contains $93 \%$ of

the nonrepetitive sequence of human chromosome 22, represented by 19,525 PCR products with an average length of 820 base pairs (bp) (Rinn et al. 2003). Since this array includes all the unique exonic, intronic, and intergenic sequences of chromosome 22, it is well suited for comprehensively studying the DNA-binding behavior of transcription factors. Briefly, STAT1 ChIPs were performed using untreated, IFN- $\gamma$-treated, and IFN- $\alpha$ treated HeLaS3 cells, whereas STAT2 ChIP DNA was prepared from the untreated and IFN- $\alpha$-treated cells (STAT2 is not induced by IFN- $\gamma$ ). Fluorescent dyes were differentially coupled to the ChIP DNA samples and hybridized to chromosome 22 arrays. Six biological replicate experiments were performed for each condition (i.e., untreated, IFN- $\gamma$ and IFN- $\alpha$ stimulations for STAT1, and IFN- $\alpha$ induction for STAT2).

The raw ChIP-chip fluorescence intensity data were processed using ExpressYourself (http://bioinfo.mbb. yale.edu/ExpressYourself), a data analysis system that normalizes and scores microarray data (Luscombe et al. 2003). After normalization and merging of biological replicates, the data were scored for the presence of differential hybridization using a $z$-score transformation as described by Quackenbush (2002). Using a stringent cutoff (see Materials and Methods), we identified many STAT1and STAT2-binding sites on chromosome 22 (Fig. 2A). The locations of these sites along chromosome 22 are diagrammed in Figure 3 (see http://array.mbb.yale.edu/ chr22/STAT). Of the 152 unique microarray features bound by STAT1 following the IFN- $\gamma$ treatment, $88 \%$ contain at least one GAS consensus sequence (TTCNN NGAA), whereas $80 \%$ of the 211 sites bound by IFN- $\alpha$ induced STAT1 have a GAS or ISRE motif (AGTTTNN NTTTCNC/T). IFN- $\alpha$-stimulated STAT2 bound to 143 fragments of chromosome 22, with a STAT consensus content of $74 \%$. These figures represent an enrichment of approximately two- to threefold over randomly selected fragments from chromosome 22 (see Materials and Methods). Targets lacking a consensus sequence were included in our analyses as binding may be occurring at nonconsensus sites or indirectly. Among the many STAT targets, the ChIP-chip studies identified four of the five known or likely STAT targets on chromosome 22. These results demonstrate that the ChIPchip assays have identified IFN-enriched populations of DNA fragments representing expected and novel STAT1- and STAT2-binding sites, the majority of which contain STAT consensus sequences.

To independently test the ChIP-chip results, quantitative PCR reactions were performed utilizing ChIP DNA. Primers were designed to amplify short segments of many STAT1- or STAT2-bound targets as well as 15 control fragments for which no enrichment was observed and 15 sites that lay below the cutoff (see Materials and Methods). The reference and IFN-treated STAT1 and STAT2 ChIP DNA samples were tested for the enriched presence of the STAT targets in the IFNinduced sample (Fig. 4A). More than 45 target regions were tested for each condition (IFN- $\gamma$ and IFN- $\alpha$ for STAT1 and IFN- $\alpha$ for STAT2). We found that a majority 
Figure 2. Scatterplots of normalized and scored replicate chromosome 22 microarray experiments from the three ChIP-chip assays $(A)$ and the four expression profiling assays $(B)$. Each point represents a fragment of the chromosome 22 array. The $\log _{2}(\mathrm{Cy} 5 / \mathrm{Cy} 3)$ ratios ( $Y$-axis) were plotted as a function of their total $\log _{10}\left(\mathrm{Cy} 5^{\star} \mathrm{Cy} 3\right)$ intensities ( $X$-axis). A local standard deviation cutoff of \pm 2.5 was used to determine the enriched hits. Red spots depict results above +2.5 standard deviations, green spots indicate the fragments with enrichment below -2.5 standard deviations, and blue spots depict the nonenriched array fragments. For the ChIP-chip in $A$, the results above the +2.5 cutoff represent IFN-induced, STAT-bound targets. In the expression assays in $B$, results with enrichment above +2.5 and below -2.5 represent fragments with IFN-up-regulated and down-regulated transcription, respectively.
A
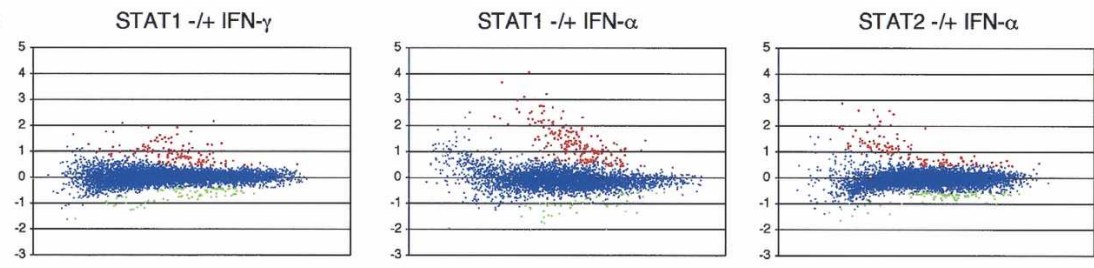

B

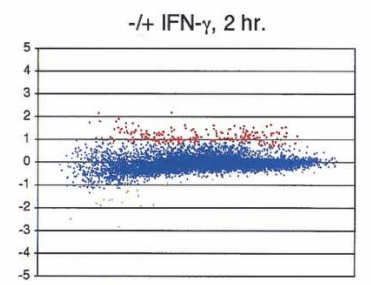

$-/+\mathrm{IFN}-\alpha, 2 \mathrm{hr}$

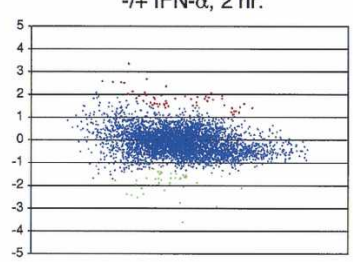

$-/+$ IFN- $\gamma, 4$ hr.

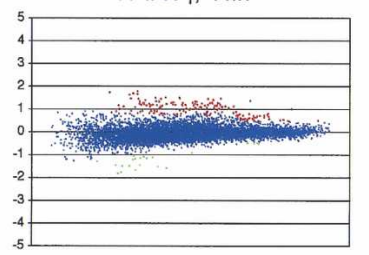

$-1+\mathrm{IFN}-\alpha, 4 \mathrm{hr}$.

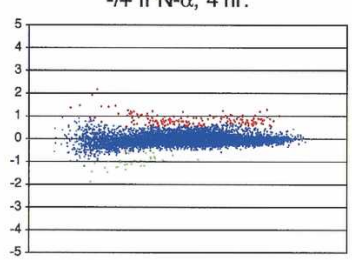

$(\sim 70 \%)$ of STAT1- and STAT2-binding sites were enriched at least twofold in IFN-treated cells relative to untreated cells (for confirmed targets, see Table 1). This confirmation rate is likely an underestimate since limitations on optimal primer design restricted the analysis of the entirety of each array fragment target. Finally, the 15 control regions and 15 other fragments below the cutoff did not exhibit any IFN-induced enrichment. Thus, the majority of the STAT1 and STAT2 DNA-binding events identified by ChIP-chip are bona fide sites in vivo.

\section{The DNA-binding patterns of STAT1 change with different IFN stimulations}

To explore the mechanisms underlying the differential utilization of STAT-binding sites, we examined how the STAT1-DNA-binding patterns differ between the two IFN treatments. Whereas several binding sites were shared between the IFN- $\gamma$ - and IFN- $\alpha$-induced STAT1 ChIP-chip results, a significant amount did not overlap. Sixty-six percent of the STAT1 sites observed in IFN- $\gamma$ induced cells were absent in the IFN- $\alpha$-treated condition, and $75 \%$ of IFN- $\alpha-$ STAT 1 sites were not present in IFN$\gamma$-treated cells. Twenty-one percent of the STAT1 sites unique to the IFN- $\alpha$-induced results overlap with STAT2-bound sites, indicating that activated STAT2 helps direct STAT1 to new locations. The remainder of the novel non-IFN- $\gamma$ STAT1-binding sites appear to be unique to STAT1 as STAT2 was not found to be present at these locations using ChIP-chip. STAT1-binding sites that were unique to each condition, as well as the STAT1- and STAT2-binding sites that were overlapping or unique in IFN- $\alpha$-treated cells, were confirmed with equal frequency by quantitative PCR. Thus, the unique and overlapping binding sites are bona fide in vivo targets.

To further address the differences in the STAT1DNA-binding patterns, we analyzed the stimulus-dependent changes in STAT-DNA binding at individual loci. Specifically, we sought to confirm four aspects of the ChIP-chip results: (1) the absence of IFN- $\alpha$-induced STAT1 binding to sites bound by IFN- $\gamma$-induced STAT1; (2) the presence of IFN- $\alpha$-induced, STAT2-independent binding of STAT1 to sites not evident in the IFN- $\gamma$-induced STAT1 results; (3) the binding of sites by both IFN- $\gamma$ - and IFN- $\alpha$-induced STAT1 without concurrent STAT2 binding; and (4) the presence of classical IFN- $\alpha$ activated STAT1:STAT2 heterodimer-DNA binding. Using quantitative PCR, we compared the enrichment of several IFN-induced STAT1 target sites in untreated, IFN- $\gamma$-treated, and IFN- $\alpha$-treated STAT1 and STAT2 ChIP DNA templates. We found that for six out of seven targets tested, STAT1 binding was only enriched in the IFN- $\gamma$-induced condition and not in the IFN- $\alpha$-treated cells. In seven out of nine different sites, we confirmed binding exclusively by IFN- $\alpha$-induced STAT1. Analysis of 16 other IFN- $\alpha-S T A T 1$ targets revealed that six were bound independent of active STAT2 and were occupied by STAT 1 in the IFN- $\gamma$-treated condition. Lastly, we also confirmed seven cases of IFN- $\alpha$-induced STAT1 and STAT2 binding to the same site. Examples of each case are presented in Figure 4B. Thus, treatment with IFN- $\alpha$ redirects STAT1 to new sites through multiple mechanisms: Binding at some sites is mediated through STAT1:STAT2 heterodimers, as expected, whereas interactions with other sites occurs in a STAT2-independent fashion (see Discussion). The STAT2-independent 


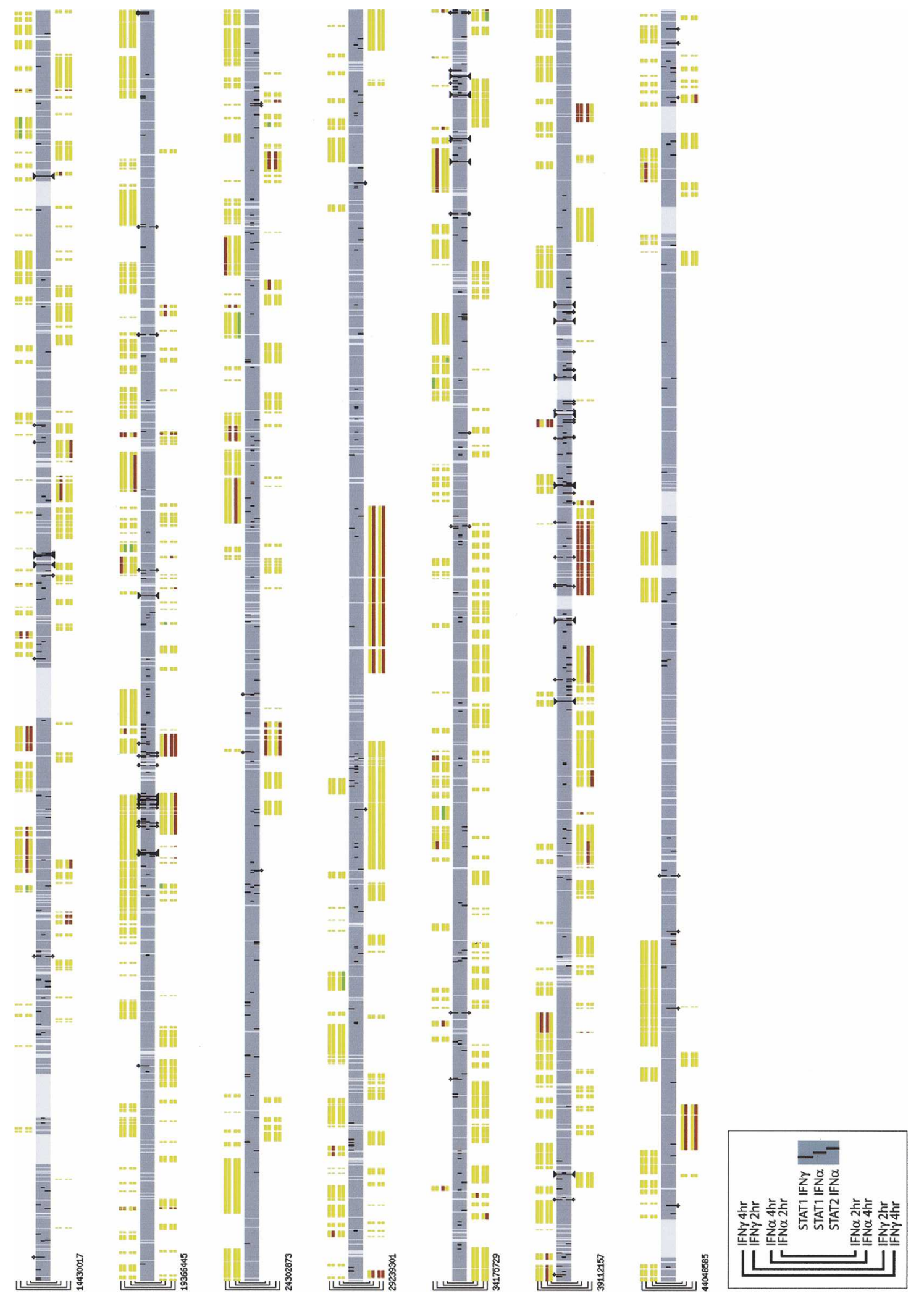

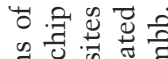

क्ष

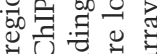

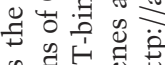

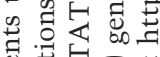

而菏

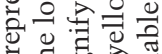

ㄴ.

$\exists$ षु

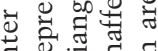

ङ

总总焉总

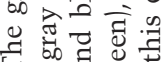

क.

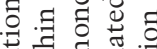

芆. $\vec{E}_{0}$

言 웜

는 0

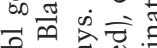

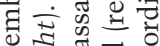

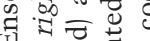

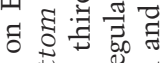

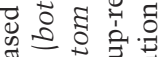

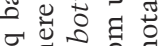

สิ่

它定跂

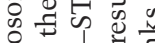

명오영

吾吾至品离

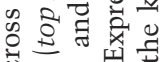

可过

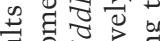

至

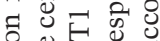

完

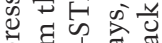

年

它空穿

तै

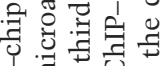

更

言导焉苞

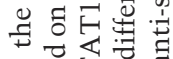

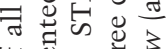

के

苛密它客

政它

ช

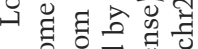

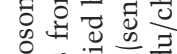

의

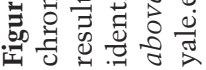


A

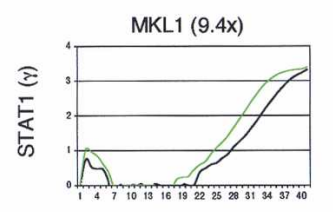

USP18 (17.4x)

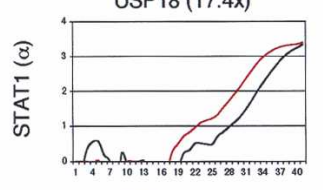

EMID1 (8.8x)

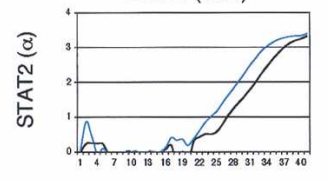

B
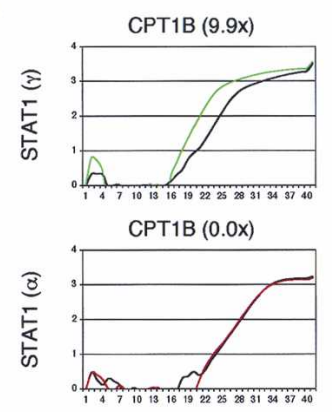

CPT1B (0.0x)

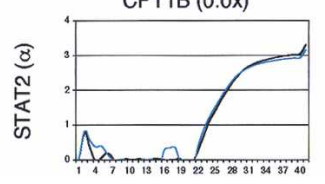

ST13 $(5.3 \mathrm{x})$

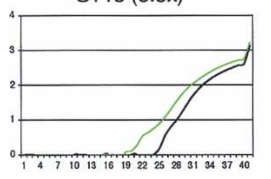

APOL1 (6.0x)

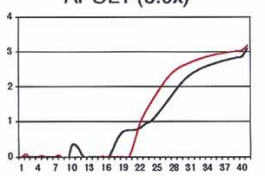

SAM50 (5.6x)

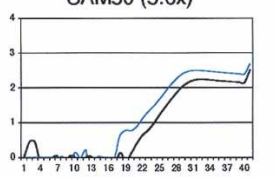

.

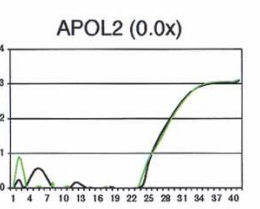

APOL2 (5.4x)

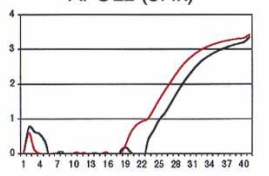

APOL2 (0.0x)

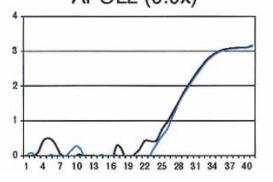

Non-enriched $(0.0 \mathrm{x})$

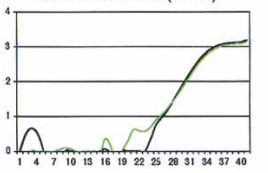

Non-enriched $(0.0 \mathrm{x})$

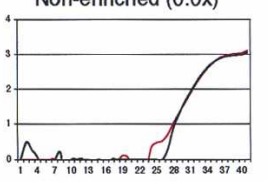

Non-enriched $(0.0 \mathrm{x})$

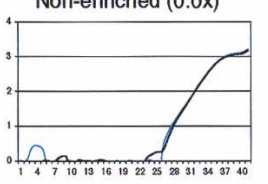

Q9NQ18 (6.0x)

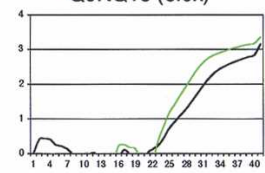

Q9NQ18 (6.5x)

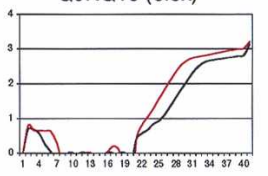

Q9NQ18 (0.0x)

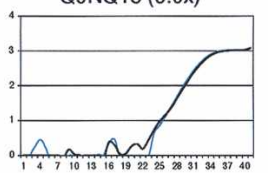

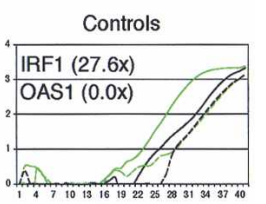

Controls

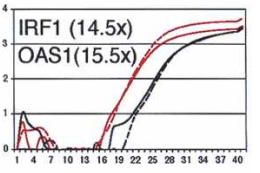

Controls

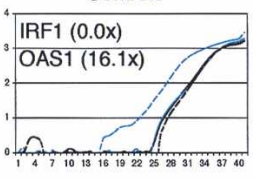

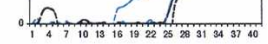

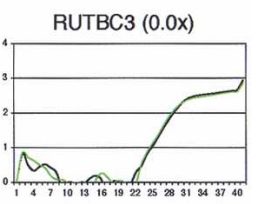

RUTBC3 $(7.4 \mathrm{x})$

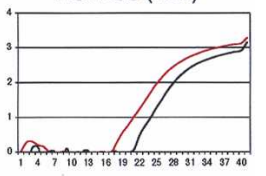

RUTBC3 (6.8x)

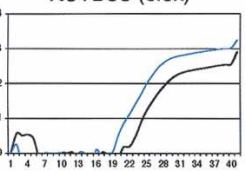

Figure 4. Quantitative PCR confirmations of ChIP-chip results. (A) IFN- $\gamma$-treated STAT1 (green), IFN- $\alpha$-treated STAT1 (red), IFN$\alpha$-treated STAT2 (blue), and untreated (black) STAT1 or STAT2 ChIP DNA was analyzed by real-time PCR using primers designed to amplify gene proximal segments of several enriched and nonenriched results from each of the ChIP-chip assays. A subset of the confirmations is shown. The known STAT-binding sites upstream of IRF1 (solid line) and OAS1 (dashed line) were tested as controls. (B) Quantitative PCR confirmations of gene-proximal sites that exhibit nonconserved STAT1 binding upon different IFN treatments. The $\log (\Delta \mathrm{Rn})$ (Y-axis) is plotted against the PCR cycle number ( $X$-axis). The fold changes are shown in parentheses.

STAT1 target fragments exhibit a twofold enrichment of GAS sites similar to that observed for STAT1 sites in IFN- $\gamma$-treated cells, suggesting that STAT2-independent STAT1 binding in IFN- $\alpha$ cells occurs at GAS sites.

STAT1 and STAT2 bind proximal to many genes on chromosome 22, many of which have IFN/STAT-related functions

The ChIP-chip assays identified several gene-proximal regions of chromosome 22 bound by STAT1 and STAT2 after IFN activation. When compared with Ensembl gene annotations, $27 \%$ of the STAT-bound regions were located proximal to genes, $82 \%$ of which were within 10 $\mathrm{kb}$ of a gene's 5' end (Fig. 3, Table 2). Eleven percent of STAT-binding sites were internal to genes. Of the internal sites, $\sim 9 \%$ intersect first exons, $42 \%$ lie in the first introns, and $\sim 16 \%$ overlap a first exon and first intron. Whereas the majority of these target genes were correlated with a single STAT-binding site, there were several patterns of gene-proximal binding where (1) a gene was found to have more than one STAT-bound site (CPT1B), (2) a single target site was identified by more than one ChIP-chip assay (RUTBC3, PPARA), and (3) two or more separate ChIP-chip assays identified different binding sites proximal to the same gene (NCF4) (Table 1). A significant portion $(-36 \%)$ of the STAT1- and STAT2-binding sites was located $>50 \mathrm{~kb}$ from any annotated genes. The PCR confirmations of the ChIP-chip results did not correlate with the position of the sites relative to the annotated loci; both distal and proximal sites as well as internal sites confirmed at similar frequencies, indicating that these are bona fide binding sites in vivo. The sites that do not lie near annotated genes may either regulate distal genes or control the expression of proxi- 
Table 1. Ensembl-annotated genes proximal to STAT1- and STAT2-binding sites on chromosome 22

\begin{tabular}{|c|c|c|c|c|}
\hline Gene & Description & $\begin{array}{c}\text { Proximity of STAT } \\
\text { binding site (bp) }\end{array}$ & $\begin{array}{l}\text { STAT bound } \\
\text { and stimulus }\end{array}$ & $\begin{array}{l}\text { Expression } \\
\text { result }\end{array}$ \\
\hline \multicolumn{5}{|c|}{ Apoptosis/proliferation/development } \\
\hline $\mathrm{BID}^{\star}$ & $\mathrm{BH}$-interacting domain death agonist & -3086 & $\mathrm{~S} 1 \alpha$ & \multirow{6}{*}{ IFN- $\gamma \uparrow$} \\
\hline CECR1 & Cat eye syndrome critical region 1 & $-9340,+72$ & $\mathrm{~S} 1 \alpha$ & \\
\hline CRKL & CRK-like protein & +152 & $\mathrm{~S} 2 \alpha$ & \\
\hline LGALS1* & Galectin-1 & +1092 & $\mathrm{~S} 2 \alpha$ & \\
\hline NEFH & Neurofilament triplet $\mathrm{H}$ protein & $-1058,+8135$ & $\mathrm{~S} 1 \alpha$ & \\
\hline PES1 & Pescadillo homolog 1 & $-3652,-2312,+10986$ & $\mathrm{~S} 2 \alpha$ & \\
\hline RUTBC3* & RUN and TBC1 domain-containing 3 & $-16042,-11433 ;-5417$ & $\mathrm{~S} 1 \gamma ; \mathrm{S} 1 \alpha, \mathrm{S} 2 \alpha$ & IFN- $\alpha \uparrow$ \\
\hline SMARCB1* & $\begin{array}{l}\text { SWI/SNF related, matrix associated, actin } \\
\text { dependent regulator of chromatin subfamily } \\
\text { B1 }\end{array}$ & -2378 & $\mathrm{~S} 2 \alpha, \mathrm{S} 1 \gamma$ & IFN- $\gamma \uparrow$ \\
\hline SSTR $3^{\star}$ & Somatostatin receptor type 3 & -1106 & $\mathrm{~S} 2 \alpha$ & \\
\hline $\mathrm{ST}_{13}{ }^{\star}$ & Hsp70-interacting protein (Hip) & $\begin{array}{l}-4176,-101,+3716 \\
-2142,+1504,+4933\end{array}$ & $\mathrm{~S} 1 \gamma ; \mathrm{S} 2 \alpha$ & IFN- $\gamma \downarrow$ \\
\hline \multicolumn{5}{|c|}{ Immune modulation/host defense } \\
\hline IGLC1 & $\operatorname{Ig} \lambda$ chain $\mathrm{C}$ regions & $-8994 ;-479,-364,-253$ & $\mathrm{~S} 1 \alpha ; \mathrm{S} 1 \gamma, \mathrm{S} 2 \alpha$ & \multirow{3}{*}{$\begin{array}{l}\text { IFN- } \gamma \uparrow \\
\text { IFN- } \alpha \downarrow\end{array}$} \\
\hline IGLL1 & Immunoglobulin $\lambda$-like polypeptide 1 & -17219 & $\mathrm{~S} 1 \alpha$ & \\
\hline NCF4* & Neutrophil cytosol factor 4 & $-1985,-967,-11120,+2689$ & $\mathrm{~S} 1 \gamma ; \mathrm{S} 1 \alpha$ & \\
\hline \multicolumn{5}{|c|}{ Ubiquitination/protein degradation } \\
\hline $\mathrm{RBX} 1^{\star}$ & RING-box protein 1 & +7005 & $\mathrm{~S} 2 \alpha$ & \multirow{3}{*}{ IFN- $\alpha \uparrow$} \\
\hline RFPL3* & Ret finger protein-like 3 & -8986 & $\mathrm{~S} 2 \alpha$ & \\
\hline UFD1L & Ubiquitin fusion degradation protein 1 homolog & +5418 & $\mathrm{~S} 1 \gamma, \mathrm{S} 1 \alpha$ & \\
\hline USP18* & Ubl C-terminal hydrolase 18 & $-16659 ;-25323$ & $\mathrm{~S} 1 \alpha ; \mathrm{S} 1 \gamma$ & IFN- $\alpha, \gamma \uparrow$ \\
\hline ZNRF3 & Novel C3HC4 type zinc finger & $-16218,+5417$ & $\mathrm{~S} 1 \alpha$ & IFN- $\alpha \uparrow$ \\
\hline \multicolumn{5}{|c|}{ Transcription } \\
\hline ATF4 & Cyclic-AMP-dependent transcription factor & -5147 & $\mathrm{~S} 1 \alpha$ & \multirow{9}{*}{ IFN- $\gamma \uparrow$} \\
\hline HDAC10 & Histone deacetylase 10 & +5036 & $\mathrm{~S} 2 \alpha$ & \\
\hline HIRA & HIRA protein (TUP1 like enhancer of split 1) & +5990 & $S 1 \alpha$ & \\
\hline $\mathrm{MKL1}^{\star}$ & Megakaryoblastic leukemia 1 & +4761 & $\mathrm{~S} 1 \gamma$ & \\
\hline POLR3H & DNA-directed RNA polymerase III subunit & -227 & $\mathrm{~S} 2 \alpha$ & \\
\hline PPARA & Peroxisome proliferator-activated receptor alpha & -7279 & $\mathrm{~S} 1 \alpha, \mathrm{S} 2 \alpha$ & \\
\hline RBM9 & RNA-binding protein 9 & $-12424,+2514$ & $\mathrm{~S} 1 \alpha$ & \\
\hline TBX1 & T-box transcription factor & -697 & $\mathrm{~S} 2 \alpha$ & \\
\hline TCF20 & $\begin{array}{l}\text { Transcription factor } 20 \text { (Stromelysin } 1 \text { PDGF- } \\
\text { responsive element-binding protein) }\end{array}$ & -2115 & $\mathrm{~S} 1 \alpha$ & \\
\hline \multicolumn{5}{|c|}{ Lipid metabolism } \\
\hline APOL1* ${ }^{\star}$ & Apolipoprotein-L1 & +277 & $\mathrm{~S} 1 \alpha$ & \multirow{4}{*}{$\begin{array}{l}\text { IFN- } \alpha \uparrow \\
\text { IFN- } \alpha \uparrow\end{array}$} \\
\hline APOL2* & Apolipoprotein-L2 & -13400 & $\mathrm{~S} 1 \alpha$ & \\
\hline $\mathrm{CPT}_{1 B}{ }^{\star}$ & Carnitine O-palmitoyltransferase I & $-10738,-787,-105$ & $\mathrm{~S} 1 \gamma$ & \\
\hline PLA2G6 & Calcium-independent phospholipase A2 & +6313 & $\mathrm{~S} 1 \alpha$ & \\
\hline \multicolumn{5}{|c|}{ Cytoskeleton/cell adhesion } \\
\hline DNAL4 & Dynein light chain 4 & $-8663,+3500,+5100$ & $\mathrm{~S} 1 \alpha$ & \multirow{6}{*}{$\begin{array}{l}\text { IFN- } \alpha, \gamma \uparrow \\
\text { IFN- } \gamma \uparrow\end{array}$} \\
\hline MYH9 & Myosin heavy chain, nonmuscle type A & -9570 & $\mathrm{~S} 1 \alpha$ & \\
\hline PARVB & $\beta$-parvin & -1435 & $\mathrm{~S} 2 \alpha$ & \\
\hline PARVG $^{\star}$ & $\gamma$-parvin & $-22778 ;+1975$ & $\mathrm{~S} 1 \alpha ; \mathrm{S} 1 \gamma$ & \\
\hline SCUBE1 & Signal peptide-CUB domain-EGF-related 1 & +5352 & $\mathrm{~S} 1 \alpha$ & \\
\hline TUBGCP6 & $\gamma$-tubulin complex component 6 & -993 & $\mathrm{~S} 2 \alpha$ & \\
\hline \multicolumn{5}{|c|}{ Signal transduction } \\
\hline CACNA1I & $\begin{array}{l}\text { Voltage-dependent T-type calcium channel } \alpha \text {-1I } \\
\text { subunit }\end{array}$ & +7215 & $\mathrm{~S} 2 \alpha$ & \multirow{4}{*}{ IFN- $\gamma \uparrow$} \\
\hline GNAZ* $^{*}$ & Guanine nucleotide-binding protein $\mathrm{G}(z)$ & $-10385,-4010$ & $\mathrm{~S} 1 \gamma, \mathrm{S} 2 \alpha, \mathrm{S} 1 \alpha$ & \\
\hline RAB36* & Ras-related protein & $-13572,-5958,+2687$ & $\mathrm{~S} 1 \gamma$ & \\
\hline RASD2 & GTP-binding protein Ras homolog & -1805 & $\mathrm{~S} 2 \alpha$ & \\
\hline \multicolumn{5}{|l|}{ Other } \\
\hline ADSL & Adenylosuccinate lyase & $-17301 ;+7419$ & $\mathrm{~S} 1 \alpha ; \mathrm{S} 1 \alpha, \mathrm{S} 1 \gamma$ & \\
\hline C1QTNF6 & $\begin{array}{l}\text { Complement } \mathrm{C} 1 \mathrm{q} \text { tumor necrosis factor- } \\
\text { related } 6\end{array}$ & +5443 & $\mathrm{~S} 2 \alpha$ & \\
\hline
\end{tabular}


Hartman et al.

Table 1. (continued)

\begin{tabular}{|c|c|c|c|c|}
\hline Gene & Description & $\begin{array}{c}\text { Proximity of STAT } \\
\text { binding site (bp) }\end{array}$ & $\begin{array}{l}\text { STAT bound } \\
\text { and stimulus }\end{array}$ & $\begin{array}{l}\text { Expression } \\
\text { result }\end{array}$ \\
\hline CACNG2 & Voltage-dependent calcium channel $\gamma-2$ & -10532 & $\mathrm{~S} 1 \alpha$ & \\
\hline CDC45L & CDC45-related protein (PORC-PI-1) & -6147 & $\mathrm{~S} 1 \alpha, \mathrm{S} 1 \gamma$ & \\
\hline CRYBA4 & $\beta$ crystallin A4 & +5980 & $\mathrm{~S} 1 \alpha$ & \\
\hline CRYBB1 & $\beta$ crystallin $\mathrm{B} 1$ & -9869 & $\mathrm{~S} 1 \alpha$ & \\
\hline CYP2D6 & Cytochrome P450 2D6 & -6054 & $\mathrm{~S} 1 \gamma$ & \\
\hline EMID $1^{\star}$ & EMI domain-containing protein 1 & $-20450,+13216 ;-1492$ & $\mathrm{~S} 1 \alpha ; \mathrm{S} 2 \alpha$ & IFN- $\alpha, \gamma \uparrow$ \\
\hline GGA1 & ADP-ribosylation factor-binding protein & +7806 & $\mathrm{~S} 2 \alpha$ & IFN- $\gamma \uparrow$ \\
\hline HORMAD2 & HORMA domain-containing 2 & $-5262,+2805$ & $\mathrm{~S} 1 \alpha$ & \\
\hline LARGE & Glycosyltransferase-like protein LARGE & +7496 & $\mathrm{~S} 1 \alpha$ & IFN- $\alpha, \gamma \uparrow$ \\
\hline MRPL40 & 39S ribosomal protein L40, mitochondrial & -6195 & $S 1 \alpha$ & \\
\hline NDUFA6 & NADH-ubiquinone oxidoreductase subunit & -858 & $\mathrm{~S} 2 \alpha$ & \\
\hline NP_071381.1* & No description & $\begin{array}{l}-5336,-1907,-302 \\
\quad+1739 ;-4119,+3773\end{array}$ & $\mathrm{~S} 2 \alpha ; \mathrm{S} 1 \gamma$ & IFN- $\alpha \uparrow$ \\
\hline NP_620169.1 & Patatin-like phospholipase domain-containing 5 & $-243,+7469$ & $\mathrm{~S} 1 \alpha$ & IFN- $\alpha, \gamma \uparrow$ \\
\hline NPTXR & Neuronal pentraxin receptor & -8955 & $\mathrm{~S} 1 \gamma$ & \\
\hline POLR2F* & $\begin{array}{l}\text { Polymerase (RNA) II (DNA directed) } \\
\text { polypeptide F }\end{array}$ & +5567 & $\mathrm{~S} 1 \alpha$ & IFN- $\gamma \uparrow$ \\
\hline PVALB & Parvalbumin $\alpha$ & -5100 & $\mathrm{~S} 2 \alpha$ & \\
\hline Q5TH50* & No description & $-11794,-4632$ & $\mathrm{~S} 1 \gamma$ & \\
\hline Q7Z2D7 & Peroxisome assembly protein 26 & $-8411 ;-9176$ & $\mathrm{~S} 1 \alpha ; \mathrm{S} 1 \alpha, \mathrm{S} 1 \gamma$ & \\
\hline Q8N1J4* & NFAT activation molecule 1 precursor & -3725 & $S 2 \alpha$ & \\
\hline Q9NQ18* & $\begin{array}{l}\text { CAP-binding protein complex interacting } \\
\text { protein }\end{array}$ & $+2766,+1197$ & $\mathrm{~S} 1 \alpha, \mathrm{S} 1 \gamma$ & IFN- $\alpha, \gamma \uparrow$ \\
\hline Q9NSQ0 & No description & +925 & $\mathrm{S} 2 \alpha$ & IFN- $\gamma \uparrow$ \\
\hline RTDR1 & Rhabdoid tumor deletion region protein 1 & $+7467,+10301$ & $\mathrm{~S} 1 \gamma$ & IFN- $\alpha, \gamma \uparrow$ \\
\hline SAM50* & SAM50-like protein CGI-51 & $-3436 ;-203 ;-202,+5485$ & $\mathrm{~S} 1 \alpha ; \mathrm{S} 1 \gamma ; \mathrm{S} 2 \alpha$ & \\
\hline SEC14L4 & SEC14-like protein 4 & +872 & $\mathrm{~S} 2 \alpha$ & \\
\hline SLC25A1 & Tricarboxylate transport protein & $-15759 ;-169$ & $\mathrm{~S} 1 \alpha ; \mathrm{S} 2 \alpha$ & \\
\hline TCN2 & Transcobalamin II precursor & +2124 & $\mathrm{~S} 2 \alpha$ & \\
\hline TRMT1* & tRNA methyltransferase 1 & -258 & $\mathrm{~S} 2 \alpha$ & \\
\hline XP_496488.1 & Similar to Ig $\kappa$ chain & $-5001,+854$ & $\mathrm{~S} 1 \alpha$ & \\
\hline YG96 (CGI-96) & No description & -8346 & $S 1 \gamma$ & \\
\hline YV03 & No description & +6128 & $\mathrm{~S} 2 \alpha$ & \\
\hline ZBED4 & Zinc finger BED domain-containing protein 4 & -4654 & $\mathrm{~S} 2 \alpha$ & \\
\hline ZCWCC1 & $\begin{array}{l}\text { Zinc finger CW-type coiled-coil domain } \\
\text { protein } 1\end{array}$ & +4121 & 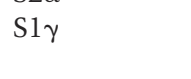 & IFN- $\alpha, \gamma \uparrow$ \\
\hline
\end{tabular}

The proximities listed represent the shortest distances between the STAT-bound array fragment and the $5^{\prime}$ end of the gene. S1 $\gamma, \mathrm{S} 1 \alpha$, and S $2 \alpha$ represent the IFN- $\gamma-S T A T 1$, IFN- $\alpha-S T A T 1$, and IFN- $\alpha-S T A T 2$ ChIP-chip results, respectively. The rightmost column indicates if the candidate target gene was also identified by the expression assays as IFN- $\alpha$ or IFN- $\gamma$ up ( $\uparrow)$ - or down $(\downarrow)$-regulated. An asterisk indicates a gene proximal to a result confirmed by qPCR.

mal, but currently unannotated transcribed loci. In summary, STAT1 and STAT2 bind to many sites in and near the promoters of genes, and in many cases, these candidate target genes are affiliated with various combinations of overlapping ChIP-chip results.

Several of the newly identified candidate STAT1 and STAT2 target genes are involved in IFN/STAT-regulated processes such as growth restraint, the promotion of apoptosis, transcription, and protein degradation, thus providing further clues as to how these factors function. One candidate related to apoptosis is BID (BH3-interacting domain death agonist), a proapoptotic BCL2 family member known to play an essential role in cell death and the suppression of tumorigenesis (K. Wang et al. 1996; Zinkel et al. 2003). The down-regulation of BID by EGF suppresses apoptosis; therefore, STAT-mediated modu- lation of BID expression presents a novel avenue for IFN induction of apoptosis (Ethier et al. 2003).

NCF4 (p40 phox) is a candidate target involved in host defense. It is an important regulatory component of NADPH-oxidase, a multicomponent system that generates superoxide anions crucial for microbicidal oxidant defense against infections (Kuribayashi et al. 2002). Interestingly, IFN- $\gamma$ modulates the expression of $p 47^{\text {phox }}$ and $p 67^{\text {phox }}$, two other components related to this mechanism (Cassatella et al. 1990; Gupta et al. 1992). NCF4 may also promote cell death, as IFN- $y$ and other cytokines can influence the regulation of apoptosis induced by reactive oxygen species. (Herrera et al. 2001; Watanabe et al. 2003).

LGALS1 (Galectin-1) is known to repress cell proliferation, induce apoptosis, and participate in immune re- 
Table 2. Percentages of STAT1- and STAT2-bound sites found within different genomic regions relative to Ensembl (build 34) gene annotations of chromosome 22

\begin{tabular}{lccc}
\hline Genomic region & $\begin{array}{c}\text { STAT1 } \\
\text { IFN- } \gamma\end{array}$ & $\begin{array}{c}\text { STAT1 } \\
\text { IFN- } \alpha\end{array}$ & $\begin{array}{c}\text { STAT2 } \\
\text { IFN- } \alpha\end{array}$ \\
\hline Relative to 5' ends (\% of total hits) & & \\
Within 10 kb & $21.1 \%$ & $19.9 \%$ & $29.4 \%$ \\
$0-10 \mathrm{~kb}$ upstream & $13.8 \%$ & $9.9 \%$ & $18.8 \%$ \\
$0-10 \mathrm{~kb}$ downstream & $7.2 \%$ & $9.9 \%$ & $10.5 \%$ \\
$>50 \mathrm{~kb}$ away & $35.5 \%$ & $34.6 \%$ & $39.2 \%$ \\
Internal to genes (\% of internal hits within $10 \mathrm{~kb})$ & \\
First exon only & $9.1 \%$ & $4.5 \%$ & $13.3 \%$ \\
First intron only & $36.4 \%$ & $31.8 \%$ & $60.0 \%$ \\
First exon/intron & $18.1 \%$ & $4.5 \%$ & $26.6 \%$ \\
\hline
\end{tabular}

sponses (Perillo et al. 1995; Rabinovich et al. 2002). Galectin-1 has been shown to activate NADPH-oxidase, which may further support the aforementioned connection between the STATs and superoxide-mediated apoptosis (Almkvist et al. 2002). In addition, Galectin-1 may initiate apoptosis via down-regulation of BCL2, providing another route from STAT activation to BCL2-mediated apoptosis (Rabinovich et al. 2000). Consistent with this type of mechanism, SSTR3 (Somatostatin receptor 3), another STAT target, and its ligand somatostatin also inhibit growth and may promote cell apoptosis via induction of p53 and BAX, a cell death agonist known to heterodimerize with BID (described above) to induce apoptosis (Sharma et al. 1996; K. Wang et al. 1996).

The ChIP-chip assays also identified genes affiliated with ubiquitin-mediated protein degradation, another IFN-related mechanism. IFN- $\gamma$ is known to assist in major histocompatibility complex (MHC) class I antigen processing and presentation by regulating the expression of various proteasome-related genes (Boehm et al. 1997). In addition, ubiquitin-targeted protein degradation is involved in most cell proliferation processes, and their misregulation has been implicated in oncogenesis (Hochstrasser 1996; Mani and Gelmann 2005). Among our candidate STAT1 and STAT2 target genes, we found RFPL3, UFD1L, RBX1, and ZNRF3, which are all related to ubiquitin ligase functions (Novelli et al. 1998; Kamura et al. 1999; Amati et al. 2002). We also identified USP18, an IFN-responsive ubiquitin isopeptidase affiliated with the IFN-regulated antiviral 2-5A system (Li et al. 2000; Tokarz et al. 2004).

\section{Expression assays reveal several IFN-regulated genes} that correlate with STAT-binding sites

To correlate STAT1- and STAT2-binding events with the expression of nearby genes, the loci of chromosome 22 that undergo changes in expression in response to IFN- $\gamma$ and IFN- $\alpha$ were determined using expression microarray analysis. Briefly, mRNA purified from HeLaS3 cells treated with IFN- $\gamma$ or IFN- $\alpha$ for 0,2 , and $4 \mathrm{~h}$ was reverse transcribed, labeled, and hybridized to chromosome 22 microarrays. These time points were chosen based on RT-PCR tests of known IFN-regulated genes (data not shown). Six biological replicate experiments were performed for each gene expression assay using independently prepared cDNA probes.

After data normalization and scoring, we identified the chromosome 22 array fragments exhibiting IFN-responsive expression patterns. All four assays (IFN- $\alpha$ or IFN- $\gamma$ for 2 and $4 \mathrm{~h}$ ) revealed many unique up-regulated regions and a small number of down-regulated loci following the IFN stimulations (Fig. 2B). Comparison of these fragments to Sanger Centre (3.1b) and Ensembl (18.34) annotations determined the genes to which the microarray results correspond. While the majority of the chromosome 22 genes were unaffected by the treatments, 20-30 genes were up-regulated by each IFN treatment and two to seven were down-regulated. (Fig. 3; Table 3). Most of these are novel IFN-responsive genes; however, we confirmed several genes known to be up-regulated by IFN, including APOL1, APOL2, APOL3, HIRA, and USP18 (Ji et al. 2003; Taylor et al. 2004). In addition, both the IFN- $\gamma$ and IFN- $\alpha$ expression assays revealed up and down-regulated expression of several predicted, related, and pseudo genes as defined by Sanger 3.1b annotations (Supplementary Table 1). Finally, we also observed IFNmodulated transcription of several regions of chromosome 22 lacking any annotations, often referred to as transcriptionally active regions (TARs) (Supplementary Table 2; Rinn et al. 2003).

Quantitative reverse transcription PCR was used to confirm the expression results. HeLaS3 cells were treated with IFN- $\gamma$ or IFN- $\alpha$ for 0,2 , and $4 \mathrm{~h}$, followed by RNA purification and reverse transcription. Normalized cDNA templates and gene specific primers were used to determine the relative quantities of many of the IFN-up and down-regulated genes (Fig. 5). The majority of the genes tested confirmed the observed IFN-induced expression changes beyond a twofold change-cutoff (for confirmed genes, see Table 3). Our assays for IFN-sensitive changes in gene expression have therefore accurately identified the up- and down-regulated expression of several genes, some known to be IFN-regulated and others with no previous association with the IFNs.

When the coordinates of all of the ChIP-chip and expression results were aligned and compared, it was observed that 72 of the STAT1- and STAT2-binding sites were proximal to genes we identified as having IFNmodulated expression levels, accounting for $52 \%$ of the gene-proximal binding sites (Fig. 3; Table 1). For example, STAT1 and STAT2 both bind upstream of SMARCB1 (or hSNF5/INI1), a protein involved in relieving repressive chromatin structures to regulate transcription as well as negatively regulating proliferation by causing cell cycle arrest (W. Wang et al. 1996; Ae et al. 2002; Zhang et al. 2002). It is also considered a tumor suppressor since mutations in this gene often result in the development of highly aggressive cancers. (Versteege et al. 1998; Biegel et al. 1999). Another example is ST13 (or HIP, HSP70-interacting protein), which was downregulated by IFN- $\gamma$ and targeted by STAT1. ST13 stimulates the chaperone activity of HSP70, thereby influencing its binding and regulation of target proteins, such as 
Hartman et al.

Table 3. Genes on chromosome 22 exhibiting IFN-sensitive expression changes

\begin{tabular}{|c|c|c|c|c|}
\hline Name & Description & IFN & Time point & Change \\
\hline A4GALT & Lactosylceramide 4- $\alpha$-galactosyltransferase & IFN- $\alpha$ & $4 \mathrm{~h}$ & $\uparrow$ \\
\hline $\mathrm{APOL}^{\star}{ }^{\star}$ & Apolipoprotein-L1 & IFN- $\alpha$ & $4 \mathrm{~h}$ & $\uparrow$ \\
\hline $\mathrm{APOL}^{\star}$ & Apolipoprotein-L2 & IFN- $\alpha$ & $4 \mathrm{~h}$ & $\uparrow$ \\
\hline APOL3* & Apolipoprotein-L3 & IFN- $\alpha$ & $4 \mathrm{~h}$ & $\uparrow$ \\
\hline ARFGAP3* & ADP-ribosylation factor GTPase-activating protein 3 & IFN- $\gamma$ & $4 \mathrm{~h}$ & $\uparrow$ \\
\hline ASCC2 & Activating signal cointegrator 1 complex subunit 2 & IFN- $\alpha$ & $4 \mathrm{~h}$ & $\uparrow$ \\
\hline BCL2L13* & Bcl-2-like 13 protein (Bcl-rambo) & IFN- $\alpha$ & $2,4 \mathrm{~h}$ & $\uparrow$ \\
\hline BCR & Breakpoint cluster region protein & IFN- $\alpha$ & $2 \mathrm{~h}$ & $\uparrow$ \\
\hline САВР7 & Calcium-binding protein 7 & IFN- $\gamma ; \alpha$ & $2 ; 4 \mathrm{~h}$ & $\uparrow$ \\
\hline CECR $1^{\star}$ & Cat eye syndrome critical region protein 1 & IFN- $\gamma$ & $4 \mathrm{~h}$ & $\uparrow$ \\
\hline CECR4 & Cat eye syndrome chromosome region, candidate 4 & IFN- $\alpha$ & $4 \mathrm{~h}$ & $\uparrow$ \\
\hline CELSR1 & Cadherin EGF LAG seven-pass G-type receptor 1 & IFN- $\gamma, \alpha$ & $4 \mathrm{~h}$ & $\uparrow$ \\
\hline CLTCL1 & Clathrin heavy-chain 2 & IFN- $\alpha$ & $4 \mathrm{~h}$ & $\uparrow$ \\
\hline $\mathrm{CSF}_{2 \mathrm{RB}}^{\star}$ & Cytokine receptor common $\beta$ chain & IFN- $\alpha$ & $4 \mathrm{~h}$ & $\uparrow$ \\
\hline DNJB7 & DnaJ homolog subfamily B member 7 & IFN- $\gamma$ & $4 \mathrm{~h}$ & $\uparrow$ \\
\hline DRG1 & Developmentally regulated GTP-binding protein 1 & IFN- $\gamma$ & $2 \mathrm{~h}$ & $\uparrow$ \\
\hline EMID1* & EMI domain-containing protein 1 precursor & IFN- $\gamma ; \alpha$ & $2 ; 4 \mathrm{~h}$ & $\uparrow$ \\
\hline GAL3ST1 & Galactosylceramide sulfotransferase & IFN- $\gamma$ & $2,4 \mathrm{~h}$ & $\uparrow$ \\
\hline GGA1 & ADP-ribosylation factor-binding protein GGA1 & IFN- $\gamma$ & $2 \mathrm{~h}$ & $\uparrow$ \\
\hline $\mathrm{HIRA}^{*}$ & TUP1-like enhancer of split protein 1 & IFN- $\gamma$ & $4 \mathrm{~h}$ & $\uparrow$ \\
\hline IGLC1 & $\operatorname{Ig} \lambda$ chain $\mathrm{C}$ regions & IFN- $\gamma$ & $4 \mathrm{~h}$ & $\uparrow$ \\
\hline $\mathrm{K} 1043^{\star}$ & TPR repeat containing & IFN- $\gamma ; \alpha$ & $4 ; 2 \mathrm{~h}$ & $\uparrow$ \\
\hline LARGE & Glycosyltransferase-like protein LARGE & IFN- $\gamma, \alpha$ & $4 \mathrm{~h}$ & $\uparrow$ \\
\hline MMP11* & Matrix metalloproteinase- 11 & IFN- $\gamma$ & $4 \mathrm{~h}$ & $\uparrow$ \\
\hline MOV10L1 & Moloney leukemia virus 10 -like protein 1 & IFN- $\gamma$ & $2 \mathrm{~h}$ & $\uparrow$ \\
\hline MTMR3 & Myotubularin-related protein 3 & IFN- $\gamma$ & $4 \mathrm{~h}$ & $\uparrow$ \\
\hline NP_055364.1 * & POM121-like protein & IFN- $\gamma ; \alpha$ & 2,$4 ; 2 \mathrm{~h}$ & $\uparrow$ \\
\hline NP_071381.1* & No description & IFN- $\alpha$ & $4 \mathrm{~h}$ & $\uparrow$ \\
\hline NP_620169.1* & Patatin-like phospholipase domain-containing 5 & IFN- $\gamma, \alpha$ & $4 \mathrm{~h}$ & $\uparrow$ \\
\hline $\mathrm{PARVG}^{\star}$ & $\gamma$-parvin & IFN- $\gamma ; \alpha$ & $4 ; 2,4 \mathrm{~h}$ & $\uparrow$ \\
\hline POLR2F* & Polymerase (RNA) II (DNA-directed) polypeptide F & IFN- $\gamma$ & $2,4 \mathrm{~h}$ & $\uparrow$ \\
\hline Q9NQ18* & CAP-binding protein complex-interacting protein 1 isoform $b$ & IFN- $\gamma ; \alpha$ & $2 ; 2,4 \mathrm{~h}$ & $\uparrow$ \\
\hline Q9NSQ0* & No description & IFN- $\gamma$ & $2 \mathrm{~h}$ & $\uparrow$ \\
\hline $\mathrm{RAB}^{2} 6^{\star}$ & Ras-related protein Rab-36 & IFN- $\gamma$ & $2 \mathrm{~h}$ & $\uparrow$ \\
\hline RBX1 & RING-box protein 1 & IFN- $\alpha$ & $4 \mathrm{~h}$ & $\uparrow$ \\
\hline $\mathrm{RTDR} 1^{\star}$ & Rhabdoid tumor-deletion region protein 1 & IFN- $\gamma ; \alpha$ & 2,$4 ; 4 \mathrm{~h}$ & $\uparrow$ \\
\hline RUTBC3* & RUN and TBC1 domain-containing 3 & IFN- $\alpha$ & $4 \mathrm{~h}$ & $\uparrow$ \\
\hline $\mathrm{SBF} 1^{\star}$ & SET-binding factor 1 & IFN- $\gamma$ & $4 \mathrm{~h}$ & $\uparrow$ \\
\hline SCUBE1 & Signal peptide-CUB domain-EGF-related 1 & IFN- $\gamma$ & $2 \mathrm{~h}$ & $\uparrow$ \\
\hline SF3A1 & Splicing factor 3 subunit 1 & IFN- $\gamma ; \alpha$ & $2 ; 4 \mathrm{~h}$ & $\uparrow$ \\
\hline SMARCB1 * & $\begin{array}{l}\text { SWI/SNE-related, matrix associated, actin-dependent regulator } \\
\text { of chromatin subfamily B member } 1\end{array}$ & IFN- $\gamma$ & $4 \mathrm{~h}$ & $\uparrow$ \\
\hline SMC1L2 & Structural maintenance of chromosome 1 -like 2 protein & IFN- $\gamma ; \alpha$ & $2 ; 2,4 \mathrm{~h}$ & $\uparrow$ \\
\hline SMTN & Smoothelin & IFN- $\gamma$ & $2 \mathrm{~h}$ & $\uparrow$ \\
\hline SREBF2 & Sterol regulatory element-binding protein- 2 & IFN- $\gamma ; \alpha$ & $2 ; 4 \mathrm{~h}$ & $\uparrow$ \\
\hline TBC1D10 & TBC1 domain family member 10 & IFN- $\gamma ; \alpha$ & $2 ; 4 \mathrm{~h}$ & $\uparrow$ \\
\hline USP18* & Ubiquitin C-terminal hydrolase 18 & IFN- $\gamma ; \alpha$ & $2 ; 4 \mathrm{~h}$ & $\uparrow$ \\
\hline XP_036729.2 & PREDICTED: ubiquitin-specific protease 41 & IFN- $\alpha$ & $4 \mathrm{~h}$ & $\uparrow$ \\
\hline $\mathrm{ZCWCC}^{*}$ & Zinc finger CW-type coiled-coil domain protein 1 & IFN- $\gamma ; \alpha$ & 2,$4 ; 4 \mathrm{~h}$ & $\uparrow$ \\
\hline ZNRF3 & PREDICTED: novel C3HC4-type Zinc finger & IFN- $\alpha$ & $4 \mathrm{~h}$ & $\uparrow$ \\
\hline GPR24 & Melanin-concentrating hormone receptor 1 & IFN- $\gamma$ & $4 \mathrm{~h}$ & $\downarrow$ \\
\hline IGLL1 * & Immunoglobulin $\lambda$-like polypeptide 1 & IFN- $\alpha$ & $4 \mathrm{~h}$ & $\downarrow$ \\
\hline IL17R* & Interleukin-17 receptor & IFN- $\alpha$ & $4 \mathrm{~h}$ & $\downarrow$ \\
\hline MAP3K7IP1 & MAPKKK 7 -interacting protein 1 & IFN- $\gamma$ & $4 \mathrm{~h}$ & $\downarrow$ \\
\hline NF2 & Merlin (Moesin-ezrin-radixin-like protein) & IFN- $\alpha$ & $2 \mathrm{~h}$ & $\downarrow$ \\
\hline PCQAP & Positive cofactor 2 glutamine/Q-rich-associated protein & IFN- $\gamma$ & $2 \mathrm{~h}$ & $\downarrow$ \\
\hline PRAME $^{\star}$ & Melanoma antigen preferentially expressed in tumors & IFN- $\alpha$ & $2 \mathrm{~h}$ & $\downarrow$ \\
\hline PTGES & Prostaglandin E synthase & IFN- $\alpha$ & $2 \mathrm{~h}$ & $\downarrow$ \\
\hline Q5R3M6 & TRIO and F-actin-binding protein & IFN- $\alpha$ & $4 \mathrm{~h}$ & $\downarrow$ \\
\hline SEC14L3 & SEC14-like protein 3 & IFN- $\alpha$ & $4 \mathrm{~h}$ & $\downarrow$ \\
\hline SLC2A11* & Solute carrier family 2 , facilitated glucose transporter 11 & IFN- $\gamma ; \alpha$ & $2 ; 4 \mathrm{~h}$ & $\downarrow$ \\
\hline SLC5A1 & Sodium/glucose cotransporter 1 & IFN- $\alpha$ & $2 \mathrm{~h}$ & $\downarrow$ \\
\hline ST13* & Hsc70-interacting protein (Hip) & IFN- $\gamma$ & $4 \mathrm{~h}$ & $\downarrow$ \\
\hline
\end{tabular}

An asterisk indicates a result confirmed by qRT-PCR. 


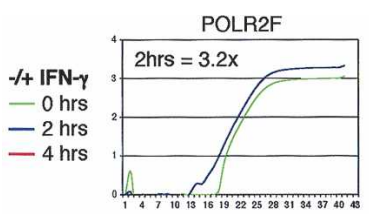

BCL2L13

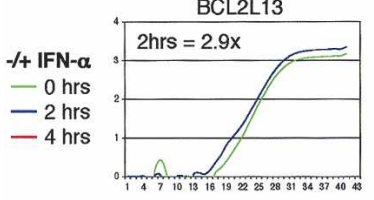

GAPDH (IFN- $\gamma)$

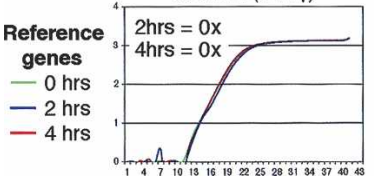

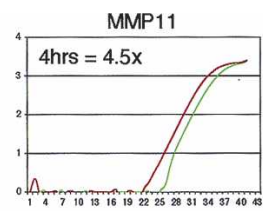

APOL1

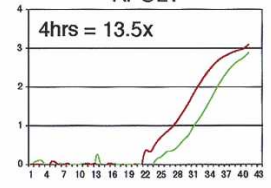

PPIA (IFN- $\gamma$ )

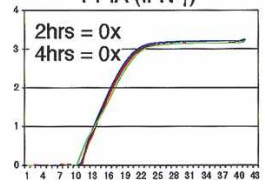

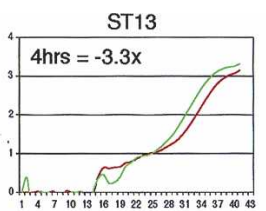

IL17R

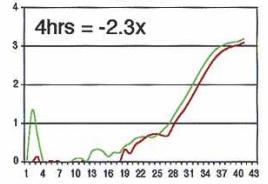

GAPDH (IFN- $\alpha)$

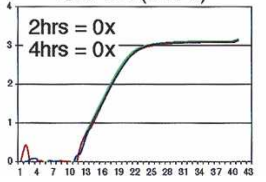

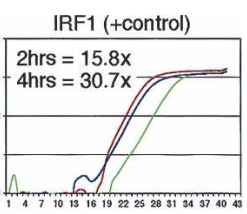

IRF1 (+control)

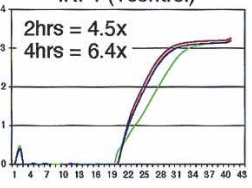

PPIA (IFN- $\alpha)$

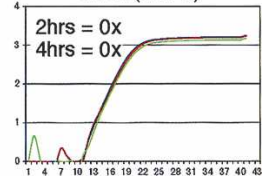

Figure 5. Quantitative RT-PCR confirmations of IFN- $\gamma$ and IFN- $\alpha$ expression assays. Normalized cDNA samples from untreated (green), 2-h IFN-treated (blue), and 4-h IFN-treated (red) cells were analyzed by real-time RT-PCR. The $\log (\Delta \mathrm{Rn})(Y$-axis) is graphed against the reaction cycle number ( $X$-axis). The fold changes were determined from the $-\Delta \Delta \mathrm{Ct}$ values calculated using GAPDH and PPIA as reference genes. IRF1 was tested as a positive control.

APAF1, AIF, and JNK, that inhibit apoptosis in response to physiologic stress (Gabai et al. 1998; Garrido et al. 2001; Nollen et al. 2001; Ravagnan et al. 2001). A decrease in HIP expression would disrupt this process, thus presenting another possible avenue for IFN-triggered cell death.

Our combined ChIP-chip and expression analysis approach also identified nearly all (four out of five) of the genes on chromosome 22 previously characterized as IFN regulated. APOL1, APOL2, HIRA, and USP18 were previously shown to be up-regulated by IFNs (Li et al. 2000; Ji et al. 2003; Taylor et al. 2004). Our expression assays found IFN-sensitive increases in the expression of these genes in addition to identifying STAT1 or STAT2 binding near their $5^{\prime}$ ends. This unified analysis of IFN/ STAT activity on chromosome 22 has therefore revealed that many STAT1- and STAT2-binding sites are located proximal to loci that exhibit IFN-influenced expression changes. In many cases STAT-DNA interactions are therefore likely directly regulating the expression of these genes. Furthermore, we demonstrated that the combination of the ChIP-chip and expression profiling microarray approaches is useful for identifying biologically relevant STAT-DNA interactions.

\section{Discussion}

Identification of the specific binding sites of a transcription factor is crucial to developing a detailed understanding of the regulation of its target genes and for characterizing how the subsequent cellular responses occur. With the ChIP-chip approach, it is possible to comprehensively study the DNA-binding behavior of individual transcription factors in any available cell type, under a variety of conditions, and over large-scale sequences. In this study we carried out ChIP-chip experiments of STAT1 and STAT2 in IFN-treated cells both to deter- mine their gene targets and to understand how STATDNA interactions are differentially selected upon different cellular stimuli. To further refine our identification of STAT1- and STAT2-regulated genes, we also performed expression profiling experiments to identify IFNsensitive changes in gene expression.

\section{ChIP-chip and expression results provide insights into IFN/STAT activities}

Our analysis of the genomic landscape surrounding the STAT1- and STAT2-binding sites introduced new mechanisms by which the IFNs and STATs may exert their effects. Consistent with the role of STAT1 and STAT2 in growth restraint and tumor suppression, several of the genes proximal to the STAT-binding sites are involved in the regulation of proliferation and apoptosis, such as BID, NCF4, LGALS1, and SSTR3. In addition, we identified candidate target genes involved in other STAT-influenced processes, such as cell adhesion, host defense, ubiquitin-mediated degradation, and transcription. The locations of the STAT1- and STAT2-binding sites were also compared with the results from the IFN$\alpha$ - and IFN- $\gamma$-induced expression assays. Seventy-two ChIP-chip target sites correlated with IFN-regulated genes, comprising $52 \%$ of the gene-proximal sites. Among these were four of the five previously reported IFN/STAT target genes on chromosome 22, thereby indicating that this integrative microarray approach accurately identifies STAT target genes. The identification of binding sites near other IFN-regulated genes therefore suggests likely new bona fide functional targets of the STATs.

In addition to identifying IFN-regulated genes with nearby STAT-binding sites, there are cases where binding and IFN regulation do not correlate. Fifty-six percent of the IFN-sensitive genes were not identified by the 
ChIP-chip assays. These either represent false negatives or genes that are require other conditions (i.e., cell type, stimulation duration, costimulation, or cofactor) to be regulated. ChIP quantitative PCR analysis of STAT1 sites bound under one condition but not bound under another (Fig. 4B) did not reveal false negatives, suggesting that this is likely to be infrequent. In addition to the identification of regulated genes that do not have binding sites, approximately half of the genes proximal to STAT1 - and STAT2-binding sites did not exhibit IFNaltered expression. Either the effect of STAT binding on expression of these genes is small (i.e., below our cutoff) or additional cofactors and/or conditions may be required for the STATs to affect expression of such genes. Studies of NF-кB also noted that transcription factor binding does not always result in alterations of gene expression (Martone et al. 2003). We suggest that the effect of transcription factor binding on gene expression is both gene and cell type specific and often requires input from multiple factors.

Several of the STAT-bound sites were not located near Ensembl or Sanger annotated loci; indeed, 36\% of the STAT1- and STAT2-bound sites were located >50 kb away from any gene. It may be that in these cases STATDNA binding occurs without subsequent biological effects or that these interactions regulate new genes that have not yet been annotated in these regions. Consistent with this latter possibility, an average of $54 \%$ of the distal ( $>50 \mathrm{~kb}$ away) STAT-binding sites lie within $5 \mathrm{~kb}$ of a transcribed region that currently lacks annotation (TAR), 10\% of which appear to be regulated by the IFNs. Perhaps several of these novel transcripts have IFN/ STAT functions.

\section{Changes in STAT1 binding upon different cellular conditions}

Further analysis of the ChIP-chip results revealed an unexpected pattern of IFN-induced STAT1-DNA binding. Since STAT1 homodimers form after both IFN- $\gamma$ and IFN- $\alpha$ stimulation, one would expect the IFN- $\gamma$-induced STAT1-binding sites to overlap with a subset of the IFN- $\alpha$-induced STAT1 sites. While our results revealed that 52 sites were bound by STAT1 in both stimulation conditions, 100 IFN- $\gamma$-induced STAT1-binding sites were absent in the IFN- $\alpha$-induced results. Closer examination of the shifting STAT1-binding profiles by quantitative PCR confirmed that IFN- $\gamma$-induced STAT1 homodimers bind sites not occupied by STAT1 upon IFN- $\alpha$ induction. Only $20 \%$ of the STAT1-bound sites unique to the IFN- $\alpha$ induction are bound by STAT2. While the lack of binding to a particular site must be interpreted cautiously, our directed PCR confirmations (Fig. 4B) further support our observed STAT1-binding patterns and the lack of STAT2 binding at many STAT1 IFN- $\alpha$ sites. In addition, the identification of most (four out of five) expected STAT target genes by the ChIP-chip assay suggests a low false-negative rate. Thus, many STAT1 "IFN- $\gamma$ sites" are not used in the IFN- $\alpha$ response, and many new STAT1 "IFN- $\alpha$ sites" become bound in a STAT2-independent manner. We suggest that binding to new sites in IFN- $\alpha$ treated cells occurs through changes in chromatin accessibility and/or the presence of additional dimerization partners (Fig. 6). The high frequency of GAS sites within the STAT2-independent STAT1 target fragments suggests that many of these sites are bound by STAT1 homodimers, thus supporting a model of differential site accessibility. The lack of IFN- $\alpha$-induced STAT1 binding to the "IFN- $\gamma$ sites" may also be due to site accessibility. Chromatin remodeling by the histone acetylases p300 and CBP may be involved in this process, as they are known to contribute to the enhancement of STAT1driven transcriptional activation (Zakharova et al. 2003). An additional novel mechanism is also likely to take place. Since the amount of STAT1 protein is similar between the HeLaS3 cells treated with IFN- $\gamma$ and IFN- $\alpha$ for $30 \mathrm{~min}$ (the ChIP-chip assay time point), the quantity of STAT1 homodimers is expected to decrease in the presence of activated STAT2 or other dimerization partners, thereby allowing only the higher affinity STAT1:STAT1 sites to be used in the IFN- $\alpha$ response. This "titration model" predicts that the levels of cofactors and binding partners will have a significant impact on DNA binding by STAT homodimers.
Figure 6. Schematic of IFN-induced STAT1-binding site selection. (A) IFN- $\gamma$ and IFN- $\alpha$ both induce STAT1 homodimers, which bind DNA (Gene A); however, we also observed IFN- $\alpha$-induced, STAT2-independent binding of STAT1 to sites not occupied by IFN- $\gamma$-induced STAT1 (Gene C). (B) Changes in binding site accessibility and/or the presence of a cooperating cofactor may account for the binding of STAT1 to new sites upon IFN- $\alpha$ treatment. Also, the binding of STAT1 to alternate dimerization partners (such as STAT2) reduces the relative quantity of STAT1 homodimers; thus, a loss of STAT1 binding to some IFN- $\gamma$-induced sites occurs.
A

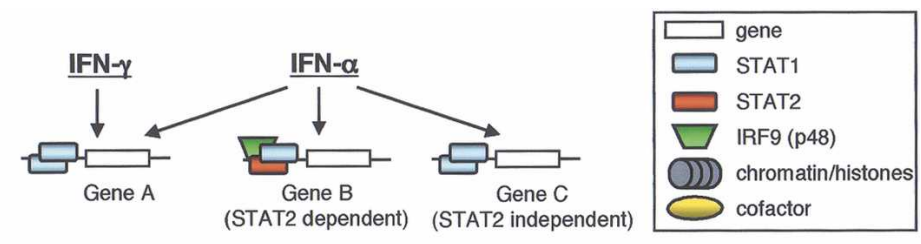

B

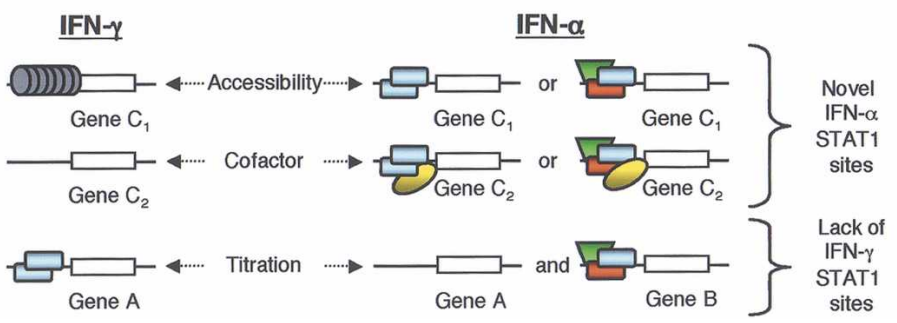




\section{Conclusion}

It has been estimated that the IFNs control the transcription of several hundred genes in humans, exerting an influence on numerous aspects of cell functioning. In this study we combined ChIP-chip and expression profiling microarray approaches to study the activities of IFN- $\alpha$, IFN- $\gamma$, STAT1, and STAT2 along an entire human chromosome. The STAT1- and STAT2-binding sites on chromosome 22 were identified, as well as the full spectrum of annotated and unannotated loci that display IFN- $\alpha$ - and IFN- $\gamma$-sensitive changes in expression. As a result, a variety of candidate genes not previously related to the IFNs or STATs were discovered. Among these were several genes that introduce new possible routes by which the IFNs and STATs may enact their antiproliferative and proapoptotic effects, allowing for the further development of models of these processes. Importantly, we have also demonstrated that the DNA-binding behavior of STAT1 homodimers is not conserved between the different IFN treatment conditions, introducing a new mechanism for the regulation of STAT1-DNA interactions and target gene selection. Ultimately, it will be of enormous value to create a complete catalog of STATcontrolled genes by expanding this approach to study the full-genome binding and expression profiles of all the STAT family members in response to different activating stimuli in several normal and disease cell types.

\section{Materials and methods}

\section{Cell culture and stimulation}

HeLaS3 cells (ATCC) were cultured in suspension in spinner flasks in S-MEM (GIBCO-Invitrogen) supplemented with glutamine, fetal bovine serum (10\%), and antibiotics (Antibiotic-Antimycotic, GIBCO-Invitrogen) at $37^{\circ} \mathrm{C}$ and $5 \% \mathrm{CO}_{2}$. Recombinant human IFN- $\gamma$ and IFN- $\alpha$ (R\&D Systems) were used at 5 $\mathrm{ng} / \mathrm{mL}$ and $500 \mathrm{U} / \mathrm{mL}$, respectively.

\section{Cell extracts, immunoprecipitations, and Western blotting}

Untreated and IFN-treated cells were washed twice in cold PBS and swollen for $15 \mathrm{~min}$ on ice in a hypotonic buffer $(20 \mathrm{mM}$ Hepes at $\mathrm{pH} 7.9,10 \mathrm{mM} \mathrm{KCl}, 1 \mathrm{mM}$ EDTA at $\mathrm{pH} 8,10 \%$ glycerol, $1 \mathrm{mM}$ DTT, $0.5 \mathrm{mM}$ PMSF, $0.1 \mathrm{mM}$ sodium orthovanadate, and protease inhibitors). Cells were broken by dounce homogenization, and the nuclei were pelleted by brief centrifugation. The nuclei were lysed in RIPA buffer $(10 \mathrm{mM}$ Tris- $\mathrm{Cl}$ at $\mathrm{pH}$ $8.0,140 \mathrm{mM} \mathrm{NaCl}, 0.025 \%$ sodium azide, $1 \%$ Triton $\mathrm{X}-100$, $0.1 \%$ SDS, $1 \%$ deoxycholic acid, 0.5 mM PMSF, 1 mM DTT, 0.1 $\mathrm{mM}$ sodium orthovanadate, and protease inhibitors) for $30 \mathrm{~min}$ on ice with repeated vortexing. Extracts were clarified by centrifugation at $14,000 \mathrm{rpm}$ for $15 \mathrm{~min}$ at $4^{\circ} \mathrm{C}$. STAT1 and STAT2 were immunoprecipitated from nuclear extracts using antiSTAT1 and anti-STAT2 C-terminal antibodies (Santa Cruz Biotechnology). Western blotting was performed using antibodies for STAT1, STAT2, phospho-Y701-STAT1, and phospho-Y689STAT2 (Upstate Biotechnology).

\section{ChIP}

For each ChIP-chip assay, $1 \times 10^{8} \mathrm{HeLaS3}$ cells were treated with IFN- $\gamma$ or IFN- $\alpha$ for $30 \mathrm{~min}$ at $37^{\circ} \mathrm{C}$ with an equal amount of cells left untreated. Cells were cross-linked with formaldehyde at a final concentration of $1 \%$ for 10 min followed by addition of glycine in PBS at a final concentration of $125 \mathrm{mM}$. Cells were collected by centrifugation and washed twice in cold $1 \times$ PBS, and nuclear-enriched extracts were prepared as described above. The lysate was sonicated with a Branson 250 Sonifier to shear the chromatin (Output 20\%, 100\% duty cycle, five 30 -sec pulses), and the samples were clarified by centrifugation. STAT1-DNA or STAT2-DNA complexes were immunoprecipitated with an anti-STAT1 or anti-STAT2 C-terminal antibody (Santa Cruz Biotechnology) overnight at $4^{\circ} \mathrm{C}$ on a neutator. Each immunoprecipitation sample was incubated with protein A-agarose (Upstate Biotechnology) for $1 \mathrm{~h}$ at $4^{\circ} \mathrm{C}$ followed by three washes with RIPA buffer and one wash with $1 \times$ PBS. The antibody-STAT-DNA complexes were eluted from the beads by addition of $1 \%$ SDS, $1 \times$ TE $(10 \mathrm{mM}$ Tris-Cl at $\mathrm{pH}$ 7.6, $1 \mathrm{mM}$ EDTA at $\mathrm{pH} \mathrm{81}$, incubation for $10 \mathrm{~min}$ at $65^{\circ} \mathrm{C}$, addition of $0.67 \%$ SDS in $1 \times \mathrm{TE}$, incubation for another $10 \mathrm{~min}$ at $65^{\circ} \mathrm{C}$, and finally gentle vortexing for $10 \mathrm{~min}$. The beads were removed by centrifugation, and the supernatants were incubated overnight at $65^{\circ} \mathrm{C}$ to reverse the cross-linking. To purify the DNA, proteinase $\mathrm{K}$ solution $(400 \mu \mathrm{g} / \mathrm{mL}$ proteinase $\mathrm{K}, 1 \times$ TE) was added, and the samples were incubated for $2 \mathrm{~h}$ at $45^{\circ} \mathrm{C}$, followed by a phenol:chloroform:isoamyl alcohol extraction and ethanol precipitation to recover the DNA. See the Supplemental Material for a more detailed protocol.

Unstimulated and IFN-stimulated STAT1 and STAT2 ChIP DNA was analyzed by PCR to test for the presence of STAT1 and STAT2 target sequences in the promoter regions of IRF1 and OAS1: IRF1 primers (Forward, 5'-CTTCGCCGCTAGCTC TACAACAG-3'; Reverse, 5'-GCTCCGGGTGGCCTCGGTT CG-3'); OAS1 primers (Forward, 5'-GGCTGGAGGTTAAAAT GCAT-3'; Reverse, 5'-GCATGCGGAAACACGTGTCTGG-3'). Reactions used $2 \times$ Taq Mastermix (Qiagen) under the following reaction conditions: $5 \mathrm{~min}$ at $94^{\circ} \mathrm{C}, 30$ cycles of $30 \mathrm{sec}$ at $94^{\circ} \mathrm{C}$, $30 \mathrm{sec}$ at $53^{\circ} \mathrm{C}, 30 \mathrm{sec}$ at $72^{\circ} \mathrm{C}$, and $10 \mathrm{~min}$ at $72^{\circ} \mathrm{C}$. PCR products were analyzed by gel electrophoresis.

\section{ChIP DNA labeling}

Amino-allyl dUTP (Sigma) was incorporated into Klenow-generated, random-primed copies of the STAT1 and STAT2 ChIP DNA using a modified version of Invitrogen's Bioprime DNA Labeling System as described by Weinmann et al. (2002). The uninduced and IFN-induced amino-allyl-modified ChIP DNA was differentially labeled with Cy dyes (Amersham Pharmacia) following the dye-coupling protocol from Ambion's Amino-allyl cDNA Labeling kit. The samples were mixed, purified, concentrated by ethanol precipitation, and resuspended in hybridization solution ( $5 \times$ SSC, $0.1 \%$ SDS, $25 \%$ formamide).

\section{Microarray hybridization}

The human chromosome 22 microarray was constructed as described (Rinn et al. 2003). Microarray slides were incubated with prehybridization solution ( $5 \times$ SSC, $0.1 \%$ SDS, $25 \%$ formamide, $1 \mathrm{mg} / \mathrm{mL} \mathrm{BSA}$ ) for $1 \mathrm{~h}$ at $42^{\circ} \mathrm{C}$. Six biological replicates were performed for each assay to obtain robust results. The arrays were rinsed with water, dried, and incubated with the labeled DNA probe mixture for $16 \mathrm{~h}$ at $42^{\circ} \mathrm{C}$. Microarrays were submerged briefly in $2 \times$ SSC to remove the LifterSlips (Erie Scientific), followed by two 5 -min washes in $2 \times$ SSC and three 5 -min washes in $0.1 \times$ SSC with gentle agitation. Microarray slides were scanned using an Axon 4000A scanner (Axon Instruments), and the raw fluorescence intensities were measured using GenePix 3.0 software. 


\section{Data normalization, scoring, and analysis}

The raw intensity measurements were normalized and scored using ExpressYourself (http://bioinfo.mbb.yale.edu/ExpressYourself; Luscombe et al. 2003). Background correction and intensity-based and spatial loss normalizations were performed, and the normalized data were filtered to remove aberrant intensity measurements. The six replicate experiments were scaled to one another to obtain robust, uniform means and variances across experiments. Scaled Cy5/Cy3 ratios for each array feature were $\log _{2}$ transformed and summarized into a single measurement via their geometric mean (Quackenbush 2002). The $\log _{2}(\mathrm{Cy} 5 / \mathrm{Cy} 3)$ ratios for each array element were plotted as a function of their total intensity $\left(\log _{10}\left(\mathrm{Cy} 5^{\star} \mathrm{Cy} 3\right)\right)$. Standard deviations of the ratio were calculated in a sliding window equal to $10 \%$ of the total number of plotted points along the $X$-axis. Each $\log _{2}$ ratio was $z$-score transformed by dividing it by its locally identified standard deviation. Fragments with local standard deviation values beyond a 2.5 cutoff $(\sim 99 \%$ confidence level) were considered to be enriched hits. To further increase the scoring stringency, we required each result to be present in seven out of 12 array features $(>80 \%$ were found in nine out of $12)$.

The consensus sequence content of the hits was compared with that of two separate randomly selected sets of array fragments using TFSEARCH to determine the relative enrichment of transcription factor-binding sites in the STAT-bound fragments.

All of the ChIP-chip and expression assay results were mapped relative to Ensembl (build 34) and Sanger Centre (3.1b) annotations for chromosome 22, as diagrammed in Figure 3. Online versions of these maps are available at http://array. mbb.yale.edu/chr22/STAT for further exploration. Click on any binding site or gene to open a window containing detailed information for that locus.

\section{Quantitative PCR of ChIP-chip results}

Unstimulated and IFN-stimulated STAT1 and STAT2 ChIP DNA samples were analyzed by quantitative PCR. Primers were designed to amplify 200-300-bp fragments tiling across a subset of the enriched target fragments, 15 nonenriched results, and 15 sites occurring in less than seven out of 12 features. Quantitative PCR reactions were performed in 96-well format using an ABI Prism 7000 Sequence Detection System and SYBR Green Master Mix (MJ Research). Cycling conditions were as follows: $10 \mathrm{~min}$ at $95^{\circ} \mathrm{C}, 40 \mathrm{cycles}$ of $10 \mathrm{sec}$ at $95^{\circ} \mathrm{C}, 1 \mathrm{~min}$ at $50^{\circ} \mathrm{C}, 1 \mathrm{~min}$ at $72^{\circ} \mathrm{C}$, and a final extension period of $10 \mathrm{~min}$ at $72^{\circ} \mathrm{C}$, followed by a $60^{\circ} \mathrm{C}-95^{\circ} \mathrm{C}$ dissociation protocol. The $-\Delta \Delta \mathrm{Ct}$ values were calculated relative to reference PCR reactions.

\section{Expression assay}

HeLaS3 cells were treated with IFN- $\gamma$ or IFN- $\alpha$ for 0,2 , and $4 \mathrm{~h}$ at $37^{\circ} \mathrm{C}$. Poly(A) RNA was prepared and concentrated by ethanol precipitation [MicroPoly(A) Pure kit, Ambion]. The mRNA samples were reverse transcribed, and the cDNA products were differentially labeled to Cy dyes (Amino-allyl cDNA Labeling kit, Ambion). The purified probes from six biological replicates were hybridized to separate chromosome 22 microarrays. Data acquisition and normalization were performed as described above. The expression of a given locus was deemed IFN- $\gamma$ or IFN- $\alpha$ induced or suppressed if an array fragment exhibiting enrichment beyond the \pm 2.5 local standard deviation cutoff overlapped a Sanger 3.1b or Ensembl (build 34) annotated exon.
Confirmation of expression profiling results

A subset of the IFN up- and down-regulated genes were confirmed by quantitative, two-step RT-PCR. Total RNA from IFN treated and untreated HeLaS3 cells was prepared (RNAqueous4PCR kit, Ambion) and reverse transcribed with AMV reverse transcriptase and oligo(dT) primers for $2 \mathrm{~h}$ at $48^{\circ} \mathrm{C}$. RNA was removed by $\mathrm{NaOH}$ hydrolysis, and the cDNAs were concentrated by ethanol precipitation. Quantitative PCR was performed as described above using the normalized cDNA samples and gene-specific primers. The $-\Delta \Delta \mathrm{Ct}$ values and fold changes were calculated using GAPDH and PPIA reference genes.

\section{Acknowledgments}

We thank Ghia Euskirchen, Rebecca Martone, and John Rinn for constructing the chromosome 22 microarray and for valuable discussions; Ken Nelson for microarray production; Susana Vidan for quantitative PCR assistance; Xin-Yuan Fu for helpful suggestions; and Anthony Borneman and Eric White for their reading and critical comments of this manuscript. This work was supported by NIH grant HG02357; A.N. is supported by an $\mathrm{NIH}$ predoctoral training grant 5 T32 GM07499.

\section{References}

Ae, K., Kobayashi, N., Sakuma, R., Ogata, T., Kuroda, H., Kawaguchi, N., Shinomiya, K., and Kitamura, Y. 2002. Chromatin remodeling factor encoded by inil induces G1 arrest and apoptosis in inil-deficient cells. Oncogene 21:31123120 .

Almkvist, J., Dahlgren, C., Leffler, H., and Karlsson, A. 2002. Activation of the neutrophil nicotinamide adenine dinucleotide phosphate oxidase by galectin-1. J. Immunol. 168: 40344041.

Amati, F., Conti, E., Botta, A., Amicucci, P., Dallapiccola, B., and Novelli, G. 2002. Functional characterization of the 5' flanking region of human ubiquitin fusion degradation 1 like gene (UFD1L). Cell Biochem. Funct. 20: 163-170.

Biegel, J.A., Zhou, J.Y., Rorke, L.B., Stenstrom, C., Wainwright, L.M., and Fogelgren, B. 1999. Germ-line and acquired mutations of INI1 in atypical teratoid and rhabdoid tumors. Cancer Res. 59: 74-79.

Boehm, U., Klamp, T., Groot, M., and Howard, J.C. 1997. Cellular responses to interferon- $\gamma$. Annu. Rev. Immunol. 15: 749-795.

Bromberg, J. and Chen, X. 2001. STAT proteins: Signal transducers and activators of transcription. Methods Enzymol. 333: $138-151$.

Bromberg, J.F., Horvath, C.M., Wen, Z., Schreiber, R.D., and Darnell Jr., J.E. 1996. Transcriptionally active Statl is required for the antiproliferative effects of both interferon $\alpha$ and interferon $\gamma$. Proc. Natl. Acad. Sci. 93: 7673-7678.

Cassatella, M.A., Bazzoni, F., Flynn, R.M., Dusi, S., Trinchieri, G., and Rossi, F. 1990. Molecular basis of interferon- $\gamma$ and lipopolysaccharide enhancement of phagocyte respiratory burst capability: Studies on the gene expression of several NADPH oxidase components. J. Biol. Chem. 265: 2024120246.

Certa, U., Seiler, M., Padovan, E., and Spagnoli, G.C. 2001. High density oligonucleotide array analysis of interferon- $\alpha 2$ a sensitivity and transcriptional response in melanoma cells. Br. J. Cancer 85: 107-114.

Der, S.D., Zhou, A., Williams, B.R., and Silverman, R.H. 1998. 
Identification of genes differentially regulated by interferon $\alpha, \beta$, or $\gamma$ using oligonucleotide arrays. Proc. Natl. Acad. Sci. 95: 15623-15628.

Durbin, J.E., Hackenmiller, R., Simon, M.C., and Levy, D.E. 1996. Targeted disruption of the mouse Stat1 gene results in compromised innate immunity to viral disease. Cell 84: 443-450.

Ethier, C., Raymond, V.A., Musallam, L., Houle, R., and Bilodeau, M. 2003. Antiapoptotic effect of EGF on mouse hepatocytes associated with downregulation of proapoptotic Bid protein. Am. I. Physiol Gastrointest. Liver Physiol. 285: G298-G308.

Euskirchen, G., Royce, T.E., Bertone, P., Martone, R., Rinn, J.L., Nelson, F.K., Sayward, F., Luscombe, N.M., Miller, P., Gerstein, M., et al. 2004. CREB binds to multiple loci on human chromosome 22. Mol. Cell Biol. 24: 3804-3814.

Gabai, V.L., Meriin, A.B., Yaglom, J.A., Volloch, V.Z., and Sherman, M.Y. 1998. Role of Hsp70 in regulation of stresskinase JNK: Implications in apoptosis and aging. FEBS Lett. 438: $1-4$.

Garrido, C., Gurbuxani, S., Ravagnan, L., and Kroemer, G. 2001. Heat shock proteins: Endogenous modulators of apoptotic cell death. Biochem. Biophys. Res. Commun. 286: 433-442.

Gupta, J.W., Kubin, M., Hartman, L., Cassatella, M., and Trinchieri, G. 1992. Induction of expression of genes encoding components of the respiratory burst oxidase during differentiation of human myeloid cell lines induced by tumor necrosis factor and $\gamma$-interferon. Cancer Res. 52: 2530-2537.

Herrera, B., Alvarez, A.M., Sanchez, A., Fernandez, M., Roncero, C., Benito, M., and Fabregat, I. 2001. Reactive oxygen species (ROS) mediates the mitochondrial-dependent apoptosis induced by transforming growth factor $(\beta)$ in fetal hepatocytes. FASEB I. 15: 741-751.

Hochstrasser, M. 1996. Ubiquitin-dependent protein degradation. Annu. Rev. Genet. 30: 405-439.

Iyer, V.R., Horak, C.E., Scafe, C.S., Botstein, D., Snyder, M., and Brown, P.O. 2001. Genomic binding sites of the yeast cellcycle transcription factors SBF and MBF. Nature 409: 533538.

Ji, X., Cheung, R., Cooper, S., Li, Q., Greenberg, H.B., and He, X.S. 2003. Interferon alfa regulated gene expression in patients initiating interferon treatment for chronic hepatitis $\mathrm{C}$. Hepatology 37: 610-621.

Kamura, T., Koepp, D.M., Conrad, M.N., Skowyra, D., Moreland, R.J., Iliopoulos, O., Lane, W.S., Kaelin Jr., W.G., Elledge, S.J., Conaway, R.C., et al. 1999. Rbx1, a component of the VHL tumor suppressor complex and SCF ubiquitin ligase. Science 284: 657-661.

Kaplan, D.H., Shankaran, V., Dighe, A.S., Stockert, E., Aguet, M., Old, L.J., and Schreiber, R.D. 1998. Demonstration of an interferon $\gamma$-dependent tumor surveillance system in immunocompetent mice. Proc. Natl. Acad. Sci. 95: 7556-7561.

Kuribayashi, F., Nunoi, H., Wakamatsu, K., Tsunawaki, S., Sato, K., Ito, T., and Sumimoto, H. 2002. The adaptor protein $\mathrm{p} 40$ (phox) as a positive regulator of the superoxide-producing phagocyte oxidase. EMBO J. 21: 6312-6320.

Leaman, D.W., Chawla-Sarkar, M., Jacobs, B., Vyas, K., Sun, Y., Ozdemir, A., Yi, T., Williams, B.R., and Borden, E.C. 2003. Novel growth and death related interferon-stimulated genes (ISGs) in melanoma: Greater potency of IFN- $\beta$ compared with IFN- $\alpha 2$. J. Interferon Cytokine Res. 23: 745-756.

Levy, D.E. and Darnell Jr., J.E. 2002. Stats: Transcriptional control and biological impact. Nat. Rev. Mol. Cell Biol. 3: 651662.

Li, X., Leung, S., Qureshi, S., Darnell Jr., J.E., and Stark, G.R.
1996. Formation of STAT1-STAT2 heterodimers and their role in the activation of IRF-1 gene transcription by interferon- $\alpha$. J. Biol. Chem. 271: 5790-5794.

Li, X.L., Blackford, J.A., Judge, C.S., Liu, M., Xiao, W., Kalvakolanu, D.V., and Hassel, B.A. 2000. RNase-L-dependent destabilization of interferon-induced mRNAs: A role for the 2-5A system in attenuation of the interferon response. $J$. Biol. Chem. 275: 8880-8888.

Luscombe, N.M., Royce, T.E., Bertone, P., Echols, N., Horak, C.E., Chang, J.T., Snyder, M., and Gerstein, M. 2003. ExpressYourself: A modular platform for processing and visualizing microarray data. Nucleic Acids Res. 31: 3477-3482.

Mani, A. and Gelmann, E.P. 2005. The ubiquitin-proteasome pathway and its role in cancer. J. Clin. Oncol. 23: 47764789.

Martone, R., Euskirchen, G., Bertone, P., Hartman, S., Royce, T.E., Luscombe, N.M., Rinn, J.L., Nelson, F.K., Miller, P., Gerstein, M., et al. 2003. Distribution of NF-кB-binding sites across human chromosome 22. Proc. Natl. Acad. Sci. 100: $12247-12252$.

Meraz, M.A., White, J.M., Sheehan, K.C., Bach, E.A., Rodig, S.J., Dighe, A.S., Kaplan, D.H., Riley, J.K., Greenlund, A.C., Campbell, D., et al. 1996. Targeted disruption of the Stat1 gene in mice reveals unexpected physiologic specificity in the JAK-STAT signaling pathway. Cell 84: 431-442.

Meyer, T., Begitt, A., Lodige, I., van Rossum, M., and Vinkemeier, U. 2002. Constitutive and IFN- $\gamma$-induced nuclear import of STAT1 proceed through independent pathways. EMBO J. 21: 344-354.

Nollen, E.A., Kabakov, A.E., Brunsting, J.F., Kanon, B., Hohfeld, J., and Kampinga, H.H. 2001. Modulation of in vivo HSP70 chaperone activity by Hip and Bag-1. J. Biol. Chem. 276: 4677-4682

Novelli, G., Mari, A., Amati, F., Colosimo, A., Sangiuolo, F., Bengala, M., Conti, E., Ratti, A., Bordoni, R., Pizzuti, A., et al. 1998. Structure and expression of the human ubiquitin fusion-degradation gene (UFD1L). Biochim. Biophys. Acta 1396: $158-162$.

Park, C., Li, S., Cha, E., and Schindler, C. 2000. Immune response in Stat2 knockout mice. Immunity 13: 795-804.

Perillo, N.L., Pace, K.E., Seilhamer, J.J., and Baum, L.G. 1995. Apoptosis of $\mathrm{T}$ cells mediated by galectin-1. Nature 378: 736-739.

Pfeffer, L.M., Dinarello, C.A., Herberman, R.B., Williams, B.R., Borden, E.C., Bordens, R., Walter, M.R., Nagabhushan, T.L., Trotta, P.P., and Pestka, S. 1998. Biological properties of recombinant $\alpha$-interferons: 40th anniversary of the discovery of interferons. Cancer Res. 58: 2489-2499.

Quackenbush, J. 2002. Microarray data normalization and transformation. Nat. Genet. 32(Suppl): 496-501.

Rabinovich, G.A., Alonso, C.R., Sotomayor, C.E., Durand, S., Bocco, J.L., and Riera, C.M. 2000. Molecular mechanisms implicated in galectin-1-induced apoptosis: Activation of the AP-1 transcription factor and downregulation of Bcl-2. Cell Death Differ. 7: 747-753.

Rabinovich, G.A., Rubinstein, N., and Toscano, M.A. 2002. Role of galectins in inflammatory and immunomodulatory processes. Biochim. Biophys. Acta 1572: 274-284.

Ramana, C.V., Chatterjee-Kishore, M., Nguyen, H., and Stark, G.R. 2000. Complex roles of Stat 1 in regulating gene expression. Oncogene 19: 2619-2627.

Ravagnan, L., Gurbuxani, S., Susin, S.A., Maisse, C., Daugas, E., Zamzami, N., Mak, T., Jaattela, M., Penninger, J.M., Garrido, C., et al. 2001. Heat-shock protein 70 antagonizes apoptosis-inducing factor. Nat. Cell. Biol. 3: 839-843. 
Ren, B., Robert, F., Wyrick, J.J., Aparicio, O., Jennings, E.G., Simon, I., Zeitlinger, J., Schreiber, J., Hannett, N., Kanin, E., et al. 2000. Genome-wide location and function of DNA binding proteins. Science 290: 2306-2309.

Rinn, J.L., Euskirchen, G., Bertone, P., Martone, R., Luscombe, N.M., Hartman, S., Harrison, P.M., Nelson, F.K., Miller, P., Gerstein, M., et al. 2003. The transcriptional activity of human Chromosome 22. Genes \& Dev. 17: 529-540.

Sharma, K., Patel, Y.C., and Srikant, C.B. 1996. Subtype-selective induction of wild-type p53 and apoptosis, but not cell cycle arrest, by human somatostatin receptor 3. Mol. Endocrinol. 10: 1688-1696.

Stark, G.R., Kerr, I.M., Williams, B.R., Silverman, R.H., and Schreiber, R.D. 1998. How cells respond to interferons. Annu. Rev. Biochem. 67: 227-264.

Taylor, M.W., Grosse, W.M., Schaley, J.E., Sanda, C., Wu, X., Chien, S.C., Smith, F., Wu, T.G., Stephens, M., Ferris, M.W., et al. 2004. Global effect of PEG-IFN- $\alpha$ and ribavirin on gene expression in PBMC in vitro. I. Interferon Cytokine Res. 24: 107-118.

Tokarz, S., Berset, C., La Rue, J., Friedman, K., Nakayama, K., Zhang, D.E., and Lanker, S. 2004. The ISG15 isopeptidase UBP43 is regulated by proteolysis via the SCFSkp2 ubiquitin ligase. J. Biol. Chem. 279: 46424-46430.

Versteege, I., Sevenet, N., Lange, J., Rousseau-Merck, M.F., Ambros, P., Handgretinger, R., Aurias, A., and Delattre, O. 1998. Truncating mutations of hSNF5/INI1 in aggressive paediatric cancer. Nature 394: 203-206.

Wang, K., Yin, X.M., Chao, D.T., Milliman, C.L., and Korsmeyer, S.J. 1996. BID: A novel BH3 domain-only death agonist. Genes \& Dev. 10: 2859-2869.

Wang, W., Cote, J., Xue, Y., Zhou, S., Khavari, P.A., Biggar, S.R., Muchardt, C., Kalpana, G.V., Goff, S.P., Yaniv, M., et al. 1996. Purification and biochemical heterogeneity of the mammalian SWI-SNF complex. EMBO J. 15: 5370-5382.

Watanabe, Y., Suzuki, O., Haruyama, T., and Akaike, T. 2003. Interferon- $\gamma$ induces reactive oxygen species and endoplasmic reticulum stress at the hepatic apoptosis. J. Cell Biochem. 89: 244-253.

Weinmann, A.S., Yan, P.S., Oberley, M.J., Huang, T.H., and Farnham, P.J. 2002. Isolating human transcription factor targets by coupling chromatin immunoprecipitation and $\mathrm{CpG}$ island microarray analysis. Genes \& Dev. 16: 235-244.

Zakharova, N., Lymar, E.S., Yang, E., Malik, S., Zhang, J.J., Roeder, R.G., and Darnell Jr., J.E. 2003. Distinct transcriptional activation functions of STAT $1 \alpha$ and STAT $1 \beta$ on DNA and chromatin templates. J. Biol. Chem. 278: 43067-43073.

Zhang, Z.K., Davies, K.P., Allen, J., Zhu, L., Pestell, R.G., Zagzag, D., and Kalpana, G.V. 2002. Cell cycle arrest and repression of cyclin D1 transcription by INI1/hSNF5. Mol. Cell Biol. 22: 5975-5988.

Zinkel, S.S., Ong, C.C., Ferguson, D.O., Iwasaki, H., Akashi, K., Bronson, R.T., Kutok, J.L., Alt, F.W., and Korsmeyer, S.J. 2003. Proapoptotic BID is required for myeloid homeostasis and tumor suppression. Genes \& Dev. 17: 229-239. 


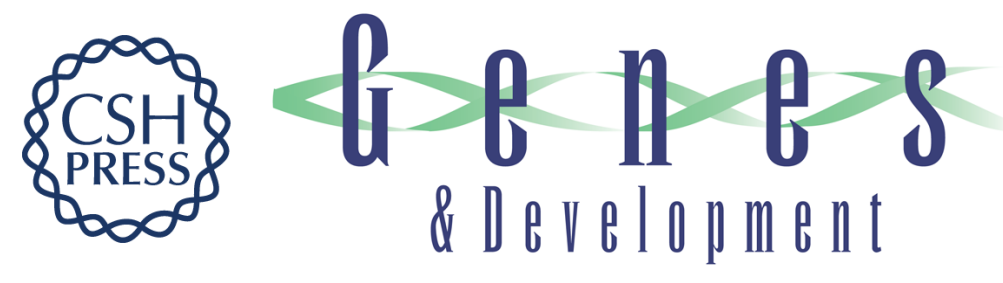

\section{Global changes in STAT target selection and transcription regulation upon interferon treatments}

Stephen E. Hartman, Paul Bertone, Anjali K. Nath, et al.

Genes Dev. 2005, 19:

Access the most recent version at doi:10.1101/gad.1371305

Supplemental http://genesdev.cshlp.org/content/suppl/2005/11/30/gad.1371305.DC1
Material

References This article cites 56 articles, 25 of which can be accessed free at:

http://genesdev.cshlp.org/content/19/24/2953.full.html\#ref-list-1

License

Email Alerting

Receive free email alerts when new articles cite this article - sign up in the box at the top

Service

right corner of the article or click here.

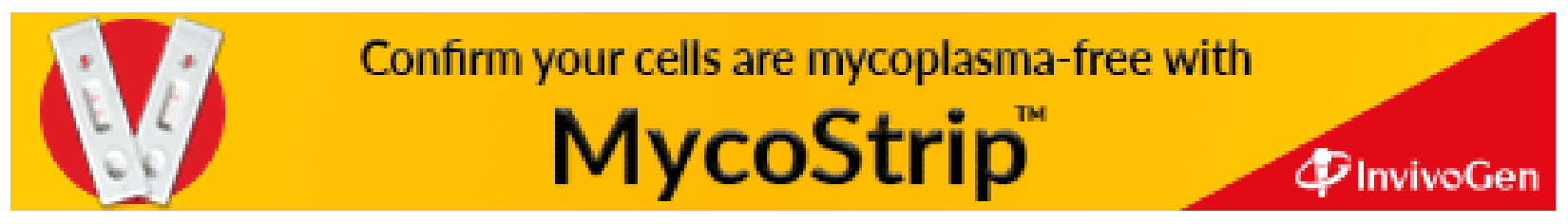

